\title{
The Effect of Idiosyncratic Risk on Mutual Fund Flows and Management Fees
}

\author{
Lorenzo Casavecchia and Hardy Hulley*
}

\begin{abstract}
We identify for the first time the crucial role played by idiosyncratic risk as a determinant of performance persistence, flow-performance sensitivity and management fees charged to fund shareholders. Using a sample of US equity mutual funds, we show that high idiosyncratic volatility indirectly captures the aggressiveness of fund investment strategies. We document that funds characterized by high idiosyncratic risk exhibit high probabilities of transitioning into the tails of the performance distribution. In particular, these high transition probabilities in performance cause funds characterized by high idiosyncratic risk to jump more frequently from one tail of the performance distribution to the other, making them appear as if they do not significantly underperform - as opposed to funds with low levels of idiosyncratic risk. Consistent with the model of Berk and Green (2004), we argue that idiosyncratic risk is a confusing factor and significantly compromises investors' ability to clearly quantify managerial skills. Since investors learn about managerial abilities from past returns and chase performance accordingly, we should expect high noise in performance to reduce the precision of investors' priors about these abilities. As a result, in the presence of switching costs and search costs, investors may optimally choose to wait to receive a better signal before (re-) allocating their capital. We document in fact that the sensitivity of flows to performance significantly and monotonically plunges for those funds engaging in high idiosyncratic risk, irrespective of their performance rankings. We also illustrate that funds with high idiosyncratic noise are relatively small (but not necessarily young) funds, with intensive portfolio rebalancing, which necessarily translates into higher management fees. Finally, we prove that when funds set their management fees, idiosyncratic risk is the determining factor, not performance, and that the previously-documented negative relationship between fees and performance does not survive after controlling for idiosyncratic noise.
\end{abstract}

KEYWORDS: Idiosyncratic volatility, performance persistence, flow-performance sensitivity, management fees JEL Codes: G10, G20, G23

This Version: March $15^{\text {th }}, 2010$

* School of Finance and Economics, University of Technology, Sydney. We have benefited from helpful comments from Phil Brown, Doug Foster, David Gallagher, Massimo Guidolin, Marcin Kacperczyk, John Knight, Steve Satchell, Massimo Scotti, Terry Walter and the seminar participants at the Queensland University of Technology, University of Technology Sydney, University of Western Australia, Melbourne Finance and Corporate Governance Conference 2010. We would like to especially thank Nahid Rahman and Mario Fiorini for their suggestions. Casavecchia gratefully acknowledges the financial support received by the School of Finance and Economics at UTS, by the Faculty of Business Research Grant (\#2010393), and by the Early Career Researcher Grant (ECRG) Scheme (\#2007002456) at UTS. The usual disclaimer applies. Please address correspondence to Lorenzo Casavecchia, School of Finance and Economics, Cnr. Quay Street and Ultimo Rd, 2007, Sydney, NSW, PO Box 123, e-mail: lorenzo.casavecchia@uts.edu.au, tel: $+61-2-95147764$. 


\section{Introduction}

The mutual fund literature has long debated the issue of whether fund managers who actively trade stocks create value to their shareholders. There is a large literature on mutual fund performance evaluation. Lakonishok, Shleifer, and Vishny (1992) document a remarkable lack of persistence in short-term performance for a sample of US equity pension funds over the period 1983 to 1989. Hendricks, Patel and Zeckhauser (1993), Goetzmann and Ibbotson (1994), and Bollen and Busse (2005) document that managerial abilities persist over a relatively short horizon. However, Grinblatt, Titman, and Wermers (1995), and Carhart (1997) argue that superior performance is simply a result of the momentum effect of Jegadeesh and Titman (1993). After controlling for common factors, Carhart (1997) shows that there is no evidence of performance persistence, with the exception of the worst performing funds. Kosowski, Timmermann, Wermers, and White (2006), Barras, Scaillet, and Wermers (2010), and Fama and French (2010) separate luck from skill in a non-normal cross section of risk-adjusted fund returns and show that performance does not seem to persist strongly over the sample period and that active funds generally produce negative after-fee returns by about the amount of their fees. ${ }^{1}$

Although performance appears to be largely unpredictable, well-documented evidence shows that investors' flows chase past performance (Gruber, 1996). In particular, several studies have indicated the existence of an empirically convex relationship between flows and performance (Ippolito, 1992, Chevalier and Ellison, 1997, Goetzmann and Peles 1997, Sirri and Tufano 1998, Zheng, 1999, DelGuercio and Tkac 2002, Lynch and Musto 2003, Nanda, Wang and Zheng 2004, Huang, Wei, Yan 2007, Gil-Bazo and Ruiz-Verdu, 2009, and Ivkovic and Weisbenner 2009) in which flows are disproportionately more sensitive to good performance than to poor performance. Taken together, the lack of performance persistence, the performance chasing behavior of investors, and the convex flow-performance relationship remain difficult to explain without postulating the existence of unsophisticated investors.

In a recent paper, Berk and Green (2004) formulate a model to reconcile many stylized facts concerning fund performance and investment flows in a rational investor framework. They argue that the competitive capital provision and the decreasing return to scale of funds provides an

\footnotetext{
${ }^{1}$ Other papers on fund performance evaluation includes Grinblatt and Titman (1992), Shukla and Trzcinka (1992), Brown and Goetzmann (1995), Malkiel (1995), Elton, Gruber, and Blake (1996), Gruber (1996), Daniel, Grinblatt, Titman, and Wermers (1997), Wermers (2000), Cohen, Coval, and Pastor (2005), Kacperczyk, Sialm, and Zheng (2005), Avramov and Wermers (2006), Berk and Tonks (2007), Huij and Verbeek (2007), Kacperczyk and Seru (2007), Mamaysky, Spiegel, and Zhang (2007), Mamaysky, Spiegel, and Zhang (2008), Cremers and Petajisto (2009), and Cremers, Petajisto, and Zitzewitz (2009).
} 
explanation for the simultaneous existence of unpredictable performance and flow-toperformance responsiveness. In equilibrium, active funds in aggregate should have zero expected performance, net of costs. They also predict that as the (idiosyncratic) noise in observed fund returns increases "investors learn less from returns about ability, and a given return triggers less response in flows". As a result, funds characterized by higher performance noise should exhibit lower return persistence and hence decreased flow-performance sensitivity, irrespective of previous observed returns.

This paper contributes to the literature in several ways, by investigating for the first time the implications of idiosyncratic noise for performance persistence, fund fee-setting, and flowperformance sensitivity. First, we show that mutual funds are characterized by large crosssectional variations in idiosyncratic risk-taking (Falkeinstein, 1996, Kosowski et al., 2006, Mamaysky, Spiegel, and Zhang, 2007; 2008, Cremers, Petajisto, and Zitzewitz, 2009). The existence of substantial heterogeneity in idiosyncratic risk induces non-normality in the crosssectional distribution of fund performance. As a result, funds with high idiosyncratic volatility tend to be characterized by high standard errors in their estimated alphas. Of course, such funds inhabit both the top and the bottom of the performance distribution. Thus, mutual funds in the tails of the performance distribution (i.e. funds with very good performance and funds with very poor performance) are not fundamentally different, as previously thought. Rather, they share the common characteristic of high levels of idiosyncratic volatility. We argue that this U-shaped relationship between performance and idiosyncratic volatility is an almost tautological consequence of the existence of heterogeneity in fund risk-taking.

The existence of a U-shaped relationship between idiosyncratic risk and performance has another important consequence: The fund probability of transitioning into the tails increases with idiosyncratic volatility. These high transition probabilities cause high idiosyncratic risk funds to jump more frequently from one tail of the performance distribution to the other. As a result, we show that higher performance transition probabilities make high idiosyncratic risk funds appear as if they do not significantly underperform on average - as opposed to funds with low idiosyncratic volatility. Thus, the high noise in performance causes a reduction in performance persistence and consequently impairs the ability of investors to clearly discriminate between skilled and unskilled managers. ${ }^{2}$ Overall, our sample of active funds earns a negative after-fee

\footnotetext{
${ }^{2}$ High transitions frequencies may also arise if, in response to extremely poor performance, high-risk funds opt to replace their portfolio managers or the investment algorithm that caused the underperformance (Heinkel and Stoughton, 1994, and Lynch and Musto, 2003). Alternatively, these funds could simply reduce their style consistency in an attempt to jump on the top of the performance ranking by the end of the reporting period (Brown, Harlow, and Starks, 1996, and Chevallier and Ellison, 1997).
} 
return, which is consistent with the equilibrium accounting perspective of Fama and French (2010).

Since investors learn about managerial abilities from previous realized excess returns and allocate their capital accordingly, we expect that an increase in idiosyncratic noise in performance should cause a reduction in the precision of investors' priors about these abilities. As a result, this noise represents an important factor to better understand why investors seem to increasingly tolerate the existence of a large minority of underperforming fund managers. Our second contribution is to show that the previously documented positive relationship between flows and performance decreases monotonically with idiosyncratic risk-taking. In particular, funds in the top quintile of idiosyncratic volatility exhibit a coefficient of flows to performance which is dramatically lower - almost a third - than that obtained for funds in the bottom quintile of idiosyncratic volatility. When we explicitly estimate the flow-performance sensitivity as the first derivative of net investment flows with respect to fund performance - conditional on the information set at $t-1$ - and regress this sensitivity against idiosyncratic volatility, we find that funds engaging in higher idiosyncratic risk experience a significant reduction in the sensitivity of flows to performance as a result of the greater noise in performance. Moreover, not only is this negative relationship between flow-performance sensitivity and idiosyncratic risk linear, but it has almost doubled in recent time due to the generally higher levels of idiosyncratic risk exhibited by contemporary funds (see also Barras, Scaillet, and Wermers, 2010). We argue that in the presence of switching costs and search costs, low flow-performance sensitivity does not necessarily imply that investors are unsophisticated. Rather, shareholders of high idiosyncratic risk funds may optimally choose to wait to receive better signals before updating their expectations about managerial skills on the basis of observed returns (Berk and Green, 2004).

Our third contribution highlights that idiosyncratic risk-taking is positively related to fund feesetting. ${ }^{3}$ Consistent with Cremers and Petajisto (2009), we show that funds with higher idiosyncratic risk are small (but not necessarily young) funds, belonging to more aggressive or active investment objectives, with more concentrated portfolios (Kacperczyk, Sialm, and Zheng, 2005). Such funds are mainly invested in small and growth stocks, and are characterized by above-average portfolio rebalancing. Since the higher management costs of intensive portfolio turnover translates into higher management fees (see also Cremers and Petajisto, 2009, and

\footnotetext{
3 Studies that have analyzed the determinants of mutual fund fee-setting include Golec (1992), Christoffersen and Musto (2002), Deli (2002), Warner and Wu (2006), Kuhnen (2005), Massa and Patgiri (2009), and Gil Bazo and Ruiz Verdu (2009). For a cross-country analysis of fee levels instead see Khorana, Servaes, and Tufano (2008).
} 
Brown, Harlow and Zhang, 2009), an increase in idiosyncratic volatility at the fund level causes a significant increase in management fees in the following filing period.

Our final contribution is to show that when the relative frequency of funds with high idiosyncratic volatility is higher in the tails of the performance distribution, then the monotonically positive relationship between fees and risk-taking automatically induces a Ushaped relationship between fees and performance, even when fees are in reality insensitive to performance. Following the seminal work of Gruber (1996), several papers, including Carhart (1997), Sirri and Tufano (1998), Harless and Peterson (1998), Wermers (2000; 2003), Kuhnen (2005), have provided indirect evidence of a U-shaped relationship between fees and performance, which suggests that funds exhibiting both good and poor performance charge above-average fees. Recently, Gil-Bazo and Ruiz-Verdu (2008; 2009) documented not only that fees are U-shaped in (expected) performance, but also that a negative relationship between management fees and performance exists and it is mostly driven by poorly performing funds. They argue that since competition in the fund management industry is fierce, competent managers will attract performance-sensitive (or sophisticated) investors, leaving the unsophisticated investors in the hands of underperforming managers (see also Christoffersen and Musto, 2002, and Berk and Tonks, 2007). As a result, underperforming funds strategically and optimally increase their fees in order to reap the full benefits of the low sensitivity to performance of unsophisticated investors. This strategic behavior of fund advisors results in a negative feeperformance relationships.

Contrary to Gil-Bazo and Ruiz-Verdu (2009), we argue that when funds set their fees, idiosyncratic risk is the determining factor, not performance. Indeed, after controlling for the idiosyncratic noise in performance, the significant relationship between fees and performance does not survive, irrespective of performance rankings. This phenomenon may be more easily illustrated by considering the conditional (on idiosyncratic risk) transition probabilities of fund performance. Imagine, for example, a fund with a high level of idiosyncratic risk and a recent track record of good performance. Such a fund would exhibit large probabilities of moving from one tail of the performance distribution to the other. If this high-risk (or aggressive) fund, which we demonstrate charges higher-than-average management fees, transitions to the bottom of the performance distribution (which is very likely), it will induce an increase in the average management fee of that quintile. Thus, the negative relationship between fees and poor performance will tend to be driven by transition frequencies of funds with higher idiosyncratic risk and also higher fees. As a robustness check, we also show that even when fund management companies leave their fees unchanged, it is still possible to observe a negative relationship 
between fees and (poor) performance. The existence of this negative relationship in the presence of constant fees cast serious doubts on the plausibility of a strategic fee-setting explanation based exclusively on fund performance.

Overall, we argue that not only does mutual fund risk-taking, in the form of idiosyncratic volatility, impose a price on fund shareholders in terms of higher (management) fees, but it also causes a reduction in both performance predictability and investors' perception of management skills, with the result of significantly compromising the performance chasing behavior of mutual fund shareholders.

The paper is organized as follows: Section I presents the data used in our analysis. Section II describes the empirical methodology adopted in this study to compute fund performance and idiosyncratic volatility. Section III discusses the implications of idiosyncratic noise for performance, investors' sensitivity, and management fees. We present our conclusion in Section IV.

\section{Data}

The data underlying this study comes from the CRSP Survivor-Bias-Free US Mutual Fund Database from January 1994 to December 2007. ${ }^{4}$ We focus on diversified US equity mutual funds and exclude fixed-income funds, money market funds, international funds and specialized sector funds ${ }^{5}$ We restrict the sample to actively managed equity mutual funds and eliminate all index and institutional funds. ${ }^{6}$ To filter the data, we employ some of the investment objectives

\footnotetext{
${ }^{4}$ The choice of the sample period is based upon the following considerations: Firstly, the CRSP dataset before the 1990's seems to be affected by an omission bias (see Elton, Gruber, and Blake., 2001) due to observations being reported with different frequencies (monthly, quarterly, or yearly) for different funds. Consequently, in the presence of mergers (or liquidations) we could underestimate (overestimate) the merger rates of those funds with monthly (yearly) data. Secondly, in 1994 the SEC approved the Rule 9460 , proposed by the NASD. According to this Rule, funds are prohibited from reporting performance rankings calculated on periods of less than one year. The NASD amendment aims to limit possible misleading marketing practices of mutual funds by insuring that these rankings are determined by the most recent calendar quarter.

${ }^{5}$ We further remove from our sample funds whose names contain strings that are inconsistent with our selected policy codes. The adopted filters are the following: B\&P, Bal, Bonds, C\&I, GS, Leases, MM, or TFM. These filters contribute to the elimination of 353 funds.

${ }^{6}$ Because the CRSP database does not provide a flag to distinguish passive from active funds, we classified and eliminated all those funds whose names contain any of the following terms: Index, Idx, Ix, Indx, Nasdaq, Dow, Mkt, DJ, S\&P, Barra, 100, 400, 500, 1000, ETF, Exchange, Vanguard, Balanced. In relation to institutional versus retail funds, the CRSP dataset has a flag to differentiate funds. However, even after removing those funds classified by the database as "institutional", we had to further filter additional funds whose names contained any of the following terms: Inst, /Y, /I, Class Y, Class I. The combined filtering of index and institutional funds (using also the CRSP "institutional fund" flag) eliminated 2369 funds.
} 
provided by CRSP. In selecting funds, we also use Strategic Insights and Lipper investment objective categories. ${ }^{7}$

We separate each fund into its various fund-classes, by recursively searching for the share class identifiers in each fund name. ${ }^{8}$ Multiple share classes with different fee schedules provide investors with a wide range of alternatives for investing in a mutual fund. Funds compete in each share-class, and hence the decomposition of a fund into its fund classes is essential for an analysis of the relation between fees and fund performance. Moreover, in order to capture the effect of the structure of the mutual fund industry, we first grouped the funds into families using the management company codes provided by CRSP, after which we manually checked the dataset to expand the number of missing codes for each management company name. This procedure increased the number of unique company codes by $15.77 \%$, when compared to those available in CRSP, and increased fund coverage by $13.16 \%$.

For a fund to be in our sample, it must have reported on total net assets under management and returns. We also considered only those funds with at least one year of reported returns. Consistent with previous research, we calculated the growth rate in net fund flows in each month as follows:

$$
\frac{T N A_{i, t}-T N A_{i, t-1} \cdot\left(1+R_{i, t}\right)-M_{i, t}}{T N A_{i, t-1}}
$$

where $T N A_{i, t}$ is the total net assets of fund $i$ in month $t, R_{i, t}$ is the after-fee return reported by fund $i$ in month $t$, and $M_{i, t}$ is the aggregate total net assets of all dead funds merged into fund $i$ in month $t^{9}$

Mutual fund fees are generally computed as percentages of total assets under management. They are charged as total operating expenses, and are computed on a daily basis. Annual operating

\footnotetext{
${ }^{7}$ More specifically, we selected funds with the following Strategic Insight objective codes: AGG, GRI, GRO, ING, SCG, or GMC. From Lipper, we selected the following codes: G, GI, LSE, MC, MR, or SG.

${ }^{8}$ Class-A funds typically charge high front-end loads and low $12 \mathrm{~b}-1$ fees, while class- B and class-C funds typically charge high $12 \mathrm{~b}-1$ fees and a contingent differed sales load. In separating the cross-section of mutual funds in cross-section of fund share classes, in addition to coding the extraction of share classes (on the basis of whether they are contained in the fund name), we also expanded the dataset by manually checking the fund names. This increased the available data by $3 \%$.

${ }^{9}$ If no TNA is available for the dead fund at the merging date, we recursively trace back the last available TNA in any of the previous three months starting from the merging date. The reason for this (see also Elton et al., 2001) is that the CRSP merger date is sometimes more than one month removed from the actual merger date (where in most instances the last TNA of the dead fund is reported in CRSP). On this point, Elton et al. show that the date mismatching errors and splits in CRSP dataset do not seem to induce any systematic pattern. However, Huang et al. (2007) reached opposite conclusions. In order to deal with this problem and reduce any effect of outliers on the coefficient estimates we windsorized the monthly growth rate in flows at the ninety-ninth percentile. Our results do not change if no windsorization is applied to the distribution of the net flows.
} 
expenses include management fees, $12 \mathrm{~b}-1$ fees, and other minor expenses, such as custodial, legal and administrative costs, which are not classified separately in the CRSP dataset. The CRSP database provides separate observations for total operating expenses and its component of $12 \mathrm{~b}-1$ fees that are charged for marketing and distribution. In our analysis, we focus only on management fees which are computed as total operating expenses net of $12 \mathrm{~b}-1$ fees. This cost serves as a proxy for expenses paid to the fund advisor.

\section{Empirical methodology}

We use several models to compute after-fee performance for the sample of funds under consideration. These include the unconditional three-factor model of Fama and French (1993), the unconditional four-factor model of Carhart (1997), and the unconditional liquidity model of Pastor and Stambaugh (2003). We also use the conditional factor model of Ferson and Schadt (1996) to allow for both observable and unobservable shifts in fund portfolios. This may allow us to estimate portfolio alphas and betas with less misspecification bias, thereby producing models with better in- and out-of-sample properties. The lagged instruments for the Ferson and Schadt model are from the CRSP dataset and include: (i) the level of the 1-month Treasury bill yield; (ii) the term spread, computed as the difference between the yield of a constant maturity 10-year Treasury bond less the yield of a 3-month Treasury bill; (iii) the dividend yield of the S\&P500; and (iv) the default spread, computed as the Moody's yield difference between Baa-rated and Aaa-rated bonds.

The model of Carhart (1997) is the representative model in this paper. We therefore report the results for this model. Results for all the other models are reported as a robustness check in some of the tables. For all other tables, the results for the other models are qualitatively similar to those presented for the Carhart (1997) model, and can be obtained from the authors. The Carhart (1997) regression model is expressed as follows:

$$
r_{i, t}=\alpha_{i}+\beta_{i} \cdot R M R F_{t}+\gamma_{i} \cdot S M B_{t}+\varsigma_{i} \cdot H M L_{t}+\eta_{i} \cdot P R 1 Y R_{t}+\varepsilon_{i, t}
$$

where $r_{i, t}$ is the month $t$ return on fund $i$ (net of T-bill rate); $R M R F_{t}$ is the month $t$ excess return on a value-weighted aggregate market proxy; and $S M B_{t}, H M L_{t}$ and $P R 1 Y R_{t}$ are the month $t$ returns on a value-weighted, zero-investment, factor mimicking portfolio for size, book-to-market equity, 
and 1-year momentum in stock returns, respectively. ${ }^{10}$ As in Carhart (1997), we employ an overlapping three-year estimation period. If less than three years of previous data is available for a specific fund in a given estimation month, then we require this fund to have at least 30 months of available observations for it to be included in the estimation. We also sorted the risk-adjusted returns into terciles of performance and compute two dummy variables: Mid, which denotes the medium performance tercile, and High, which denotes the top performance tercile. Splitting fund performance into three separate groups enables us to decompose the sensitivity of the dependent variable (fees) to performance across the performance ranks.

Since idiosyncratic volatilities are unobservable in traditional factor models, we need to use a proxy to perform our empirical tests. We follow Malkiel and Xu (2006), and Ang, Hodrick, Xing, and Zhang (2006; 2009), and use as our measure of pure idiosyncratic volatility the standard deviation of the monthly residuals, $\sigma\left(\varepsilon_{i, t}\right)$, relative to the unconditional Carhart (1997) four-factor model. ${ }^{11}$ We obtain exactly the same conclusions when other models are used to compute the unsystematic risk of a mutual fund. ${ }^{12}$ We would like to emphasize that this measure of volatility is to be interpreted as a proxy for cross-sectional variation in idiosyncratic risk-taking of mutual funds that standard risk factor models, such as Fama and French (1993) and Carhart (1997) models, do not capture as a result of the assumption that idiosyncratic risk is irrelevant since it can be diversified away. However, several asset pricing models in the literature allow for the presence of idiosyncratic risk (see Merton, 1987, Lucas, 1994, Heaton and Lucas, 1996, and Malkiel and $\mathrm{Xu}, 2006)$ due to the presence of investors holding undiversified portfolios (Falkeinstein, 1996, Kacperczyk, Sialm, and Zheng, 2005, and Huang, Sialm, and Zhang, 2009). Finally, we acknowledge that the residual from our conditional and unconditional factor models could also capture some omitted factors in addition to our measure of idiosyncratic risk. Therefore, we are cautious in interpreting these residuals from each factor model as a measure of idiosyncratic risk of that specific model and not others.

\footnotetext{
${ }^{10}$ The data used to compute risk-adjusted returns are obtained from Kenneth French's website. We thank Kenneth French for making it available.

${ }^{11}$ In order to account for the autocorrelation in the residuals, we also estimated idiosyncratic risk using the model proposed by French, Schwert, and Stambaugh (1987). Our findings do not change as a result of the high correlation (0.98) between the alternative measure proposed by French et al. and our standard deviation of the monthly residuals. In addition, our measure of unsystematic risk is computed on a lowfrequency (monthly) basis in order to have a longer period of the analysis since the mutual fund return daily data in CRSP commences only from early 1999. Moreover, Goyal and Santa-Clara (2003) document that low-frequency and high-frequency volatilities are very closely related (the correlation coefficient is 0.82 ) over a very long sample period from July 1962 to December 1999.

${ }^{12}$ One might argue that our measure of idiosyncratic risk may simply proxy for the level of liquidity of mutual fund portfolios. Consistent with Malkiel and Xu (2006), our findings do not change even after controlling for liquidity factors using the unconditional models of Pastor and Stambaugh (2003), and Sadka (2006).
} 
To examine the relationships between fund idiosyncratic risk and performance and fees and performance, we pool the time-series and cross-sectional data and use a Fama and Macbeth (1973) estimation. Since the timing of fee-setting by mutual funds is crucial, we employ the actual date range for the fee information of each fund (rather than an arbitrary calendar date for all funds). We also use a fixed-effect approach and include year-dummies to ensure that the estimated coefficients capture the cross-sectional relationships between variables, without possible distortions induced by the correlation of the residuals across different funds (crosssectional dependence). We include untabulated dummy variables for investment objectives and fund share classes in the regression. We control for small fund effect (Chen, Hong, Huang, and Kubik, 2004), by including a dummy variable, Small, which equals 1 if the fund is in the bottom $5 \%$ of the cross-sectional distribution of TNA. In order to isolate the effect of stellar funds (Nanda, Wang, and Zheng, 2004, Huang, Wei, and Yan, 2007, and Gil-Bazo and Ruiz-Verdu, 2009), we use the dummy variable Star, which equals 1 if the fund is part of a family comprising one (or more) funds whose performance is in the top $5 \%$ of the risk-adjusted return distribution.

We estimate the statistical significance of the coefficients using the Fama and Macbeth (1973) time-series standard errors. Furthermore, since the assumption of independent residuals of OLS regression is often violated in panel data (particularly in the case of a panel of mutual funds), we decided to cluster the standard errors of estimates. We remain uncommitted about the form of the correlation within clusters, and produce standard errors clustered by fund, time, and fund and time (see Petersen, 2008). Clustering in two dimensions produces standard errors with less bias.

\section{Summary Statistics}

In Table I, we present annual summary statistics for our sample of US diversified equity mutual funds. The average values of the variables are consistent with previous studies and are reported before we impose to each fund to have at least 36 months of available observations. Requesting 36 months of observations limits the possibility that our results be driven by young incubation funds (see Evans, 2009). The mean net flow growth rate is around $16 \%$, with a standard deviation of about $54 \%{ }^{13}$ The average age of a fund is almost 7 years since its first report to the SEC with a percentile deviation that ranges between 1.6 and 63 years of operations. PA fund family comprises approximately 23 funds, on average. The reason for the skewed

\footnotetext{
${ }^{13}$ The exclusion of the extreme $1 \%$ of the distribution of net flows to control for the potential effect of outliers and errors in the merge and liquidation dates in the CRSP dataset generates a linearly interpolated level of flows in the bottom $1 \%$ (top $99 \%$ ) of the distribution of $-57 \%$ (232.8\%).
} 
distribution of the number of funds per family (see percentiles 1, 25, and 50) is that single-fund families (i.e. single series) receive a 1 for this variable. The mean management fee calculated over 43,487 fund-year observations is $1.14 \%$ with a $0.41 \%$ standard deviation, while the mean operating expense (management fee plus $12 \mathrm{~b}-1$ fee) is $1.62 \%$ with a $0.57 \%$ standard deviation. The Carhart (1997) risk-adjusted return estimated over a 36-month window clearly highlights that funds underperform their benchmarks on average by about the same amount as the fees charged to investors (see also Lakonishok, Shleifer, and Vishny, 1992, Elton, Gruber, Das and Hlavka, 1993, Carhart, 1997, Wermers, 2000, Bollen and Busse, 2005, Kosowski et al., 2006, and GilBazo and Ruiz-Verdu, 2009). Moreover, the distribution of returns indicates that there is a small number of funds with superior information (or extraordinary luck). However, the positive impact of these high-performing funds on the distribution is more than offset by funds with poor stockpicking abilities (or bad luck). We also document the statistics of the idiosyncratic volatility. Funds tend to be undiversified; their performance is driven by an average level of unsystematic volatility of $1.6 \%$ compared to a $4.33 \%$ of total volatility. Figure 1 reports the time series plot of the average cross-sectional idiosyncratic volatilities calculated using low frequency (monthly) data for the sample period December 1992 to December 2007. The idiosyncratic volatility is computed as the standard deviation of the residuals from a Carhart (1997) four-factor model. We also compute the idiosyncratic volatility following the approach proposed by French, Schwert, and Stambaugh (1987) where we adjust $\sigma(\varepsilon)$ for the autocorrelation in monthly returns (lightcoloured line). The correlation coefficient between these two measures is around 0.98 over the entire sample period.

\section{Results}

\section{A. The effect of idiosyncratic risk on performance persistence}

The first part of this section provides empirical evidence for the existence of a U-shaped relationship between idiosyncratic risk and performance, for funds in our sample. The second part documents the effect of performance transition probabilities conditional on idiosyncratic volatility on investors' uncertainty with respect to management skills. Finally, the third part of this Section proffers a justification for the assumption that idiosyncratic risk-taking indeed varies substantially across funds as a result of the cross-sectional variation in the aggressiveness of their investment strategies. 


\section{A.1 The U-shaped relationship between idiosyncratic volatility and performance}

In Table II we use a contingency table of initial and subsequent performance rankings to analyze the persistence of performance for our sample of open-ended diversified equity mutual funds. Following Carhart (1997), we first rank funds into decile portfolios, based on their unconditional risk-adjusted returns over the previous three years. Funds in decile 1 (10) are those in the top (bottom) of the return distribution. Over the following year we then compute the average characteristics of these portfolios, as well as the parametric and bootstrapped significance of their performance. We require all funds to have at least 36 months of available observations. In Column (v) we report the one-tailed Newey-West (1987) parametric $t$-statistic of portfolio alpha. The parametric test documents the absence of fund performance persistence. Since standard errors are calculated under the assumption that the residual of a least-square estimation are independent, have common variance over time, and do not cluster, the existence of a U-shaped relationship between fund performance and idiosyncratic volatility (in ranking period) as that documented in Column (xiv) would obviously constitute a departure from this assumption (see also Lehmann and Modest, 1988).

Since fund unsystematic risk clusters in the tails of the return distribution, in Column (vii) we report the results of a bootstrap to control for non-normalities in individual fund residuals, which could imply non-normalities in the cross-section of $t$-statistics reported in Column (v). ${ }^{14}$ The bootstrapped $t$-statistics of alpha indicates that, after controlling for non-normality, there is no trace of managerial skills over the period 1994-2007. This result is not surprising: the bootstrap corrects for the presence of clusters of high-risk and low-risk mutual funds which can generate a cross-sectional distribution of alphas that has thinner tails compared to a normal distribution, which is assumed instead in the parametric $t$-statistics. ${ }^{15}$ These findings are very similar to those documented by Fama and French (2010) and Barras, Scaillet, and Wermers (2010). Barras et al find that over a period close to ours (1990-2006) the proportion of skilled funds has decreased

\footnotetext{
${ }^{14}$ In the calculation of the bootstrapped p-values of the $t$-statistics of alphas (documented in column $v i$ ) we follow a procedure analogous to the bootstrap algorithm proposed by Kosowski et al (2006) in the case of performance persistence test. In an unreported result, we also repeat the analysis with formation period of 60 months. Our conclusions related to fund skills do not change. Moreover, our use of bootstrapped tstatistics is motivated by the fact that analyzing fund skills on the basis of estimated alphas may be inappropriate due to the diversity in mutual fund risk leverage.

${ }^{15}$ Thus, in absence of a bootstrap we would underestimate the rejection region for the null hypothesis of no performance. We would also like to stress that this bootstrap methodology represents only a diagnostic test correction hence it may not yield useful forecasts if the underlying model is ex ante mispecified (see also Mamaysky, Spiegel, and Zhang, 2007).
} 
dramatically to only $2 \%$ of "hot hands" funds. Thus, skilled managers have become exceptionally rare. There are two possible related explanations for this phenomenon. Over the period from 1993 to 2005, Kostovetsky (2008) provide original evidence that mutual funds have experienced a "brain drain" of top managerial talent to the more profitable hedge fund industry. We add that the tremendous growth in the asset under management and the product differentiation in the mutual fund industry over the past 20 years has been characterized by the entry of more mediocre fund managers, who can prosper and survive in the industry as a result of the high unsystematic noise in their fund's performance. This noise corresponds to what Barras, Scaillet and Wermers refer to as "false discoveries", which make it impossible to clearly determine the true skills of fund managers. Such noise therefore protects unskilled managers from easy identification. Moreover, we argue that this unsystematic noise not only impairs the ability of investors to judge managerial skills, but it could also increase the search costs of new fund managers in case the board of directors would like to terminate the existing advisory contract.

\section{A.2 Idiosyncratic volatility, transition probability, and investors' confusion}

Another insight into the implications of a U-shaped relationship between idiosyncratic risk and performance is provided in Table III, where we compute the transition probabilities of portfolio performance, conditional on deciles of idiosyncratic risk. In Panel A we sort realized returns into terciles $\left(T_{1}, T_{2}\right.$, and $\left.T_{3}\right)$ in each year, over the entire sample period, and analyze the performance transition across terciles over every two consecutive years. ${ }^{16}$ In all, for each decile of idiosyncratic volatility we compute nine transition probabilities describing the evolution of fund performance from one year to the next. These transition densities are denoted as: $\mathrm{T}_{l, t-1}-\mathrm{T}_{1, t}$, $\mathrm{T}_{1, t-1}-\mathrm{T}_{2, t}, \mathrm{~T}_{1, t-1}-\mathrm{T}_{3, t}, \mathrm{~T}_{2, t-1}-\mathrm{T}_{1, t}, \mathrm{~T}_{2, t-1}-\mathrm{T}_{2, t}, \mathrm{~T}_{2, t-1}-\mathrm{T}_{3, t}, \mathrm{~T}_{3, t-1}-\mathrm{T}_{1, t}, \mathrm{~T}_{3, t-1}-\mathrm{T}_{2, t}$, and $\mathrm{T}_{3, t-1}-\mathrm{T}_{3, t}$. So, for example, the empirical transition probability denotes as $\mathrm{T}_{1, t-1}-\mathrm{T}_{3, t}$ (in Column (iii)) describes the proportion of funds that moved from the bottom performance tercile in year $t-1\left(\mathrm{~T}_{1, t-1}\right)$ to the top tercile in year $t\left(\mathrm{~T}_{3, t}\right)$. In Panel B we repeat the same exercise, this time computing the transition probabilities over three years. This device allows us to highlight the frequency of funds shifting across the tails of the performance distribution, and we immediately observe how the propensity for dramatic shifts in performance increases with increased idiosyncratic risk. Consider, for instance, the case of portfolios with low idiosyncratic volatility (decile 1): the percentage of such funds persisting in the middle ranking $\left(\mathrm{T}_{2, t-1}-\mathrm{T}_{2, t}\right)$ is equal to 31.2 percent (Column (v)). However,

\footnotetext{
${ }^{16}$ We also computed the transition matrix using Fama and French (1993), Carhart (1997), and Ferson and Schadt (1996) risk-adjusted returns and obtain qualitatively similar results to those reported in table III.
} 
when we focus on funds with high idiosyncratic volatility (decile 10), we find that a greater proportion of funds tend to cluster in the extremes of performance distribution. In particular, conditioning on funds with high idiosyncratic volatility, we observe a propensity for these funds to jump from one tail of the performance distribution to the other. Indeed, both the relative frequency of funds passing from the bottom to the top tercile $\left(\mathrm{T}_{1, t-1}-\mathrm{T}_{3, t}\right)$ in Column (iii) and that of funds passing from the top to the bottom tercile $\left(\mathrm{T}_{3, t-1}-\mathrm{T}_{1, t}\right)$ in Column (vii) increase almost monotonically from 3.8 to 15 percent and from 4.7 to 17 percent, respectively, as we move from low to high deciles of idiosyncratic risk. In particular, when we restricts our attention to funds with high idiosyncratic risk, we see that a total of 32 percent of all funds oscillate between the tails of the performance distribution from one year to the next.

The difference between decile 10 and decile 1 illustrates this point even more clearly. The change in the distribution densities from one year to the next totals $24 \%$ (11.2\% in Column (iii) plus $12.3 \%$ in Column (vii)) which almost balances the drop in the relative probability of those funds sitting in the middle part of the distribution (-28.4\% in Column (v)). Moreover, between $40 \%$ and $50 \%$ of the funds populating the tails of the performance distribution in decile 10 completely shifts from one extreme to the other of the performance distribution, hence higher unsystematic risk-taking contributes to greater investors' confusion in relation to fund expected performance. Fama and French (2010) suggest that even if skilled managers exists, they are "buried" into the performance distribution by those lucky managers who pull up the extreme right tails of the distribution of after-fee $\alpha$ or $t(\alpha)$. These lucky managers with high idiosyncratic volatility can produce positive performance even if they do not make any stock-selection efforts. Thus, it is not surprising that performance persistence tests have a downside. If funds are simply ranked on performance, their allocation to performance portfolios would be largely driven by idiosyncratic noise. This noise constitutes an important factor to better understand why investors seem to increasingly tolerate the existence of a large minority of underperforming fund managers. We will return on this point in Section B.

\section{A.3 Idiosyncratic risk as a measure for the aggressiveness of investment objectives}

Since the cross sectional variation in idiosyncratic risk may be induced by the variety of investment strategies adopted by fund managers, in this sub-section we aim to better understand how idiosyncratic risk varies relative to fund investment objectives. Teo and Woo (2001) suggest that the substantial variation in mutual fund style returns is not spanned by variations in stock characteristics across styles, and that differences in managerial abilities are better captured by 
style-adjusted return metrics. On the same line, Brown and Goetzmann (1997) evidence that at any one time mutual funds exhibit substantial lack of consistency in their investment strategies with obvious implications for performance evaluation (see also Chan, Chen, and Lakonishok, 2002). Cremers and Petajisto (2009) argue that fund performance cannot be described only by the extent of tracking error (idiosyncratic volatility), but also by the active share proportion of the fund, which ultimately depends on the investment strategy of that fund. In particular, they document that each level of idiosyncratic volatility spans high variation in fund active shares and that, as expected, active share is negatively related to fund size. Kosowski et al (2006) indicates that herding behavior can obviously induce possible cross-sectional correlations in residual risk among funds as a result of funds holding concentrated portfolios on similar industries or stocks.

In Table IV we examine the exposure of funds with different investment objectives to idiosyncratic volatility. ${ }^{17}$ In Panel A, we first sort funds according to their Carhart (1997) riskadjusted returns and assign them to performance quintiles. We then compute for each investment objective the frequencies (relative to the total number of funds belonging to each investment objective) of funds belonging to each performance quintile. Consistent with the findings of Table III, funds with investment objectives which are commonly categorized as high risk-taking objectives (namely, GMC, SCG, and AGG), are those more likely to populate the tails of the performance distribution. In fact, the inter-quintile differences (Q1-Q3 and Q5-Q3) are monotonically increasing in those funds which possibly hold heavy positions in relatively few stocks or industries (Kacperczyk, Sialm, Zheng, 2005). Cremers and Petajisto (2009) specifically test the relationship between idiosyncratic volatility and industry concentration, and conclude that high idiosyncratic volatility often arises from fund active bets on industries.

In Panel B, we examine the characteristics of funds grouped according to their investment objectives in order to establish whether idiosyncratic risk is a proxy for cross-sectional variations in risk exposure of each investment strategy. Not surprisingly, portfolio of funds with higher average idiosyncratic volatility are those that not only evidence more concentrated portfolios (GMC, SCG, and AGG) but also a lower propensity to maintain style-consistency, as captured by the higher within-category dispersion in idiosyncratic risk. ${ }^{18}$ In particular, the variation within investment objectives is much larger than the variation across investment objectives. Thus, the cross-sectional separation obtained with idiosyncratic volatility goes beyond the standard

${ }^{17}$ The investment objectives are those from Strategic Insight. In particular, income and growth funds (ING), growth and income funds (GRI), large growth funds (GRO), mid-cap growth funds (GMC), smallcap growth funds (SCG), and large aggressive growth funds (AGG).

${ }^{18}$ Our measure of dispersion in fund idiosyncratic risk is very similar to the return-based measure of style consistency (1-RSG) proposed by Brown, Harlow and Zhang (2009). A high dispersion signals lower style consistency of the fund. 
classification of fund investment objectives. Furthermore, funds engaging in more aggressive strategies are also relatively smaller funds ( $\$ 440$ million), with intensive turnover (beyond $100 \%$ ) and above-average management fees (almost 1.3\%)

\section{B Characteristics and performance of idiosyncratic risk portfolios}

\section{B.1 Characteristics of idiosyncratic risk portfolios}

In this section we analyze the characteristics and performance of portfolios sorted on idiosyncratic volatility. In particular, we first rank funds into portfolios, according to their most recent levels of idiosyncratic risk, estimated over the previous 36 months. Portfolio 1 (5) comprises funds with the lowest (highest) idiosyncratic volatility. We then compute the return of each portfolio as the equally-weighted average return of all constituent funds over the next month after portfolio formation, in order to guard against potential endogeneity issues. ${ }^{19}$ On the resulting time series of monthly portfolio returns we then run the Fama and French (1993), Carhart (1997), Pastor and Stambaugh (2003), and Ferson and Schadt (1996) factor models. ${ }^{20}$ Table VI summarizes the average fund characteristics and factor loadings for these portfolios. The results are consistent with those of Table $\mathrm{V}$, in that management fees increase monotonically with idiosyncratic risk-taking. In particular, the low idiosyncratic risk portfolio (Quintile 1) has an average fee of 91 basis points, while the high idiosyncratic risk portfolio (Quintile 5) has an average fee of almost 140 basis points. Funds in the top quintile portfolio also exhibit significantly higher loadings on the size (SMB) and growth (HML) factors. On the other hand, no significant difference arises in relation to the level of momentum and liquidity across the five portfolios. Moreover, the top quintile portfolio, by idiosyncratic volatility, comprises funds which are smaller in size (average TNA of $\$ 463$ million) relative to funds in the bottom quintile portfolio (average TNA of $\$ 1.28$ billion). The tabulated average fund age (since inception) is constant - between 9 and 10 years across all five portfolios - so fund age does not proxy for differences in idiosyncratic risk level. ${ }^{21}$

\footnotetext{
${ }^{19}$ As a robustness check, we estimated the portfolio risk-adjusted returns by separating the non-overlapping formation periods from the subsequent estimation periods in order to further limit reverse causality. The qualitative aspects of our results do not change.

${ }^{20} \mathrm{We}$ also repeated the analysis by using deciles with no particular difference in our conclusions.

${ }^{21}$ It is also interesting to note that our high idiosyncratic volatility funds are most likely those populating both risk-shifting portfolios in Huang, Sialm, and Zhang (2009) and denoted as RS1 and RS5. In fact, the characteristics of our high idiosyncratic risk portfolios (small funds, above average turnover, and portfolio
} 


\section{B.2 Performance of idiosyncratic risk portfolios and investors' confusion effect}

Since high idiosyncratic risk funds are characterized by higher conditional transition probabilities of performance, which cause them to oscillate relatively more frequently from one to the other extreme of the cross-sectional performance distribution - and hence evidence lower performance persistence - we should expect greater investors' confusion with respect to the true level of managerial skills. Table VII reports the effect of transition probabilities on monthly (after-fee) performance of portfolios sorted by idiosyncratic risk. In panel A we form idiosyncratic risk portfolios on the entire sample, in Panel B and C we also control for whether funds have below- (Small) or above- (Large) average TNA, and below- (Young) or above- (Old) average fund age, respectively.

Consistently with previous findings in the literature, Panel A evidences that the entire crosssection of mutual funds (All funds) underperforms by about the same amount as the fees. However, when funds are separated according to their idiosyncratic volatility, the portfolio of funds with the lowest level of idiosyncratic risk (Quintile 1) is characterized by a significantly negative after-fee performance, while the portfolio of funds with the highest level of idiosyncratic risk (Quintile 5) is characterized by a still negative but now insignificant performance. This result persists, even after controlling for macroeconomic shocks (in Column (vi)) and liquidity innovations (in Column (vii)). As expected, high idiosyncratic risk will cause the estimation of fund performance to be characterized by less certainty due to the high standard error in performance. It also follows that the difference between high and low idiosyncratic volatility portfolios is not significant. Since these results may vary according to the size and age of the funds, in Panel B and C we repeat the same analysis by separating funds in Small versus Large, and Young versus Old: Regardless of fund size or fund age, high idiosyncratic volatility portfolios are characterized by an estimated risk-adjusted performance which appears to compensate investors for the above average management fees.

In Figure 2 we examine the sources of this insignificant underperformance of high idiosyncratic risk funds, by computing the kernel densities of after-fee returns across three portfolios of lagged idiosyncratic risk. In particular, funds are first sorted on the basis of their lagged idiosyncratic volatility and assigned to quintiles. For quintile 1, three, and five, we then plot the probability distribution functions for the Carhart (1997) risk-adjusted returns (Panel A) and the realized raw returns (Panel B), for each of the three portfolios of idiosyncratic volatility.

concentration in small and growth stocks) are also those shared by a simple combination of the two high idiosyncratic risk portfolios (RS1 and RS5) formulated by Huang et al (2009). 
As expected, funds with higher idiosyncratic risk exhibit greater non-normality in the distribution of their returns. The result is an increase in the mass of the tails of the performance distribution, for both estimated alpha and realized returns. Thus, the tails of (risk-adjusted and raw) performance distribution increasingly attract funds with higher levels of unsystematic risk. ${ }^{22}$

\section{B.3 Idiosyncratic risk-taking as a driver of the convex flow-performance relationship}

If an increase in the conditional transition probabilities in performance - induced by high idiosyncratic risk - disguises the true level of managerial skills, we should expect fund flows to be progressively less responsive to (good or bad) performance for funds characterized by aboveaverage idiosyncratic volatility. We test this hypothesis in Table VII by regressing the yearly percentage growth rate in net money flows $(N M F)$ against several fund characteristics and performance. In all columns but column (iii), fund performance is computed as the Carhart (1997) risk-adjusted return. In order to capture the convexity of the flow-performance relationship, we interact risk-adjusted returns with two dummy variables $I_{M}$ and $I_{H}$, which indicate that the fund is in the middle or top performance tercile, respectively. In column (iii), instead, performance is computed using the fractional rankings, a la Sirri and Tufano (1998).

As expected, fund flows are positively related to past (relative) performance. The loading in column (i) of $N M F_{i, t}$ on lagged performance is significantly positive and equal to 1.64 . Nevertheless, this relationship remains convex, since flows into top-performing funds are disproportionally more sensitive to relative performance than flows out of funds inhabiting the bottom tercile of the performance distribution (refer to columns (iii) and (iv)). In addition, in agreement with Gallaher, Kaniel and Starks (2005), Sigurdsson (2005), and Gil-Bazo and RuizVerdu (2009), our results document a flow-performance relationship that is more linear than in the case of Sirri and Tufano. This difference may be the likely outcome of the different periods considered for the analysis.

If unsystematic volatility is a major driver of the convexity of the flow-performance relationship, we should expect this convexity to increase with the level of risk-taking of funds. In column (v) to (vii) we use different models to test this hypothesis. In line with the model of Berk and Green (2004), we see that when performance is characterized by high idiosyncratic noise, the sensitivity of flows to (good or bad) performance substantially decreases. The significant decrease in the sensitivities of flows to performance in all columns is staggering - for instance,

\footnotetext{
${ }^{22}$ We would like to thank Massimo Guidolin for suggesting this test.
} 
using a fixed-effect model with panel-corrected standard errors (column (vi)), we observe that the flow-performance sensitivity drops from 2.8 for low-noise funds to only 0.9 for high-noise funds.

\section{B.4 The impact of idiosyncratic volatility on the flow-performance sensitivity}

In this section we explicitly quantify the sensitivity of $N M F_{i, t}$ to performance in order to examine how it varies with respect to increasing levels of idiosyncratic volatility. In particular, we first estimate the loadings of fund net money flows $\left(N M F_{i, t}\right)$ on several fund characteristics, as documented in Table VII, using the following regression:

$$
\begin{aligned}
N M F_{i, t}= & \lambda_{0}+\delta_{1} \operatorname{Perf}_{i, t-1}+\delta_{2} \operatorname{Perf}_{i, t-1} D_{M, i, t-1}+\delta_{3} \operatorname{Perf}_{i, t-1} D_{H, i, t-1} \\
& +\delta_{4} \operatorname{Perf}_{i, t-1} \operatorname{Age}_{i, t}+\sum_{s=1}^{L} \gamma_{s} X_{s, i, t-1}+\eta_{i, t}
\end{aligned}
$$

where $\operatorname{Perf}_{i, t-1}$ is the fund $i$ (net-of-fee) four-factor alpha in period $t-1, \mathrm{Age}_{i, t-1}$ is fund $i$ logarithmic age since inception, $D_{M, i, t-1}\left(D_{H, i, t-1}\right)$ is a dummy variable which indicates whether the fund is in the middle (top) tercile of performance in previous period. The variable $X_{j, i, t-1}$ comprises several lagged control variables $j(j=1 \ldots L)$ to capture fund characteristics: logarithm of fund TNA $\left(\log _{-} T N A_{i, t-1}\right)$, logarithm of fund age (Fund_Age $\left.e_{i, t-1}\right)$, number of funds in the family (N.Funds_Family $y_{i, t-1}$ ), minimum of fund aggregate sales or aggregate purchases of securities (Turnover $_{i, t-1}$ ), fund volatility of realized returns over the previous 12 months (Volatility ${ }_{i, t-1}$ ), management fees (Mgmt fee $\left.e_{i,-1}\right)$, distribution fees (12b-1 fees plus $1 / 7^{\text {th }}$ of the front-end-loads), fund flows $\left(\right.$ Flows $\left._{i, t-1}\right)$, and dummy variables for small funds, share classes and investment objectives of the funds. We use the interaction term $\operatorname{Perf}_{i, t-1}$ Age $_{i, t}$ to capture the lower (higher) sensitivity of flows to performance for older (younger) funds as documented by Chevalier and Ellison (1997). We include the distribution fees among the control variables since several papers have documented the hauling effect of distribution fees on the asset growth of mutual funds (Sirri and Tufano, 1998, Jain and Wu, 2000, Nanda, Wang, and Zheng, 2005, Barber, Odean, and Zheng, 2005, Huang, Wei, and Yan, 2007). The sensitivity measure (denoted by $\Phi_{i, t}$ ) is then the first derivative of expected flows with respect to fund performance $\left(\partial E\left(N M F_{i, t} \mid I_{i, t-1}\right) / \partial P e r f_{i, t-1}\right)$, given the information set $I_{i, t-1}$.

Table VIII reports the coefficients of the regression between the estimated sensitivity of investors' flows $\left(\Phi_{i, t}\right)$ and lagged fund idiosyncratic volatility $\left(\sigma(\varepsilon)_{i, t-1}\right)$. We run several models: Fama-Macbeth $(F-M)$ robust standard errors (1973), year and fund fixed-effect $(F-E)$ with panel- 
corrected standard errors (Petersen, 2009), and between-effects $(B-E)$. We also run the $F-M$ model in the two sub-periods from 1994 to 2000 (column (viii)), and from 2001 to 2007 (in column (ix)), in order to further quantify possible changes in the loadings of the flowperformance sensitivity in response to time-dependent variations in the level of idiosyncratic volatility.

Overall, the flow-to-performance sensitivity is significantly and negatively related to fund idiosyncratic noise in performance. As a result, the convexity of the flow-performance relationship increases substantially when funds engage in greater risk-taking, due to the decrease in the precision of investors' (average) priors regarding management (expected) performance at time $t$. An increase in idiosyncratic volatility by $1 \%$ in period $t-1$ would cause a decrease in investors' sensitivity by about $1.5 \%$ (column (i)). Thus, an increase (decrease) in fund idiosyncratic risk would trigger a weaker (stronger) response in investors' flows, irrespective of whether fund track record is (extremely) good or bad. Furthermore, this negative relationship is linear given the insignificance of the coefficient of the dependent variable $(\Phi)$ on the squared idiosyncratic volatility term in column (ii).

Huang, Wei, and Yan (2007) show that the sensitivity of flows to performance increases for star funds due to their lower participation costs $(P C)$ and hence better visibility. If funds with higher idiosyncratic risk "hit the jackpot" and enter by pure chance the exclusive category of the star funds, they would enjoy greater flow-performance sensitivity. The implication is that if we do not control for these participation costs, we would underestimate the extent of the negative relationship between investors' flow sensitivity and idiosyncratic risk. As a proxy for participation costs we use a dummy variable, Star, which equals 1 if the fund is part of a family comprising one or more funds ranking in the top 5\% of the performance distribution in that year (Huang, Wei, and Yan, 2007, and Gil-Bazo and Ruiz-Verdu, 2009). We then re-estimate the flow-performance sensitivity after adding the interaction term between performance and participation costs in equation (2). In column (iii), (v), and (vii) we document the loading of flowperformance sensitivity on idiosyncratic volatility. As expected, after controlling for participation costs, the loading of the dependent variable $(\Phi)$ on idiosyncratic risk drops significantly (-4.03). Now, an increase in idiosyncratic volatility by $1 \%$ in period $t-1$ would cause a decrease in investors' sensitivity by about $4 \%$. This conclusion does not change when other models are used instead of the model in column (ii).

We also run the Fama-Macbeth model by separating the sample into the two sub-periods from 1994 to 2000 (column (v)) and from 2001 to 2007 (column (vi)). Consistent with the pattern of idiosyncratic volatility documented in Figure 1, the decrease in the flow-performance 
sensitivity in the later period is caused by the higher average level of idiosyncratic volatility in performance after the year 2000 (see also Campbell, Lettau, Malkiel, and Xu, 2001).

\section{Are fees really contingent on fund performance? The indirect effect of idiosyncratic volatility}

We previously documented that funds characterized by higher idiosyncratic volatility and more aggressive strategies charge investors above-average management fees. Since these funds are also those experiencing a less elastic investors' demand - as a result of large performance dispersion which causes greater investors' confusion about the level of management skills - our results seem similar to those obtained by Gil-Bazo and Ruiz-Verdu (2009). These authors argue that (underperforming) funds facing a less elastic demand would strategically charge higher (management) fees to their shareholders in an attempt to maximize their compensation, hence causing a negative relationship between managerial compensation and fund performance.

In this section, however, we approach the problem more obliquely, by asking the following question: Could it be that we are actually seeing something different when we observe the relationship between fees and performance? Our central hypothesis is that the observed feeperformance relationship may in fact be an unanticipated side-effect of the existence of high idiosyncratic volatility, without necessarily assuming any strategic behavior on the part of the funds or any lack of investors' sophistication in relation to fund fee-setting. In particular, we demonstrate that the anomalous relationship between fees and performance is a necessary consequence of the existence of a monotonically positive relationship between fees and idiosyncratic risk. The existence of high noise in performance (as evidenced in Section A) is then what makes fees to appear as if they were negatively related to poor performance.

\section{C.1. Management fees as a price for higher idiosyncratic risk-taking}

We start in Table IX by first forming quintile portfolio of funds based on ranked idiosyncratic volatility. We then further separate these portfolios in quintiles based on the following fund characteristics: turnover, age, logarithm of fund TNA, and logarithm of fund family TNA. The result is a cross tabulation of 25 portfolios, for each of which we calculate the average management fee in the following year. In the first two Panels (A and B) of Table V, we condition 
idiosyncratic volatility portfolios by size of the fund $\left(T N A_{t-1}\right)$ and size of the family of funds $\left(\right.$ Family $T N A_{t-1}$ ). As a fund grows in size, the adviser realizes economies of scale and scope, since the costs of processing transactions and providing services to investors decrease as a percentage of total assets. This cost reduction is significant and seems to be transferred to the fund shareholders, at least partially. Even after controlling for these fund characteristics, idiosyncratic volatility continues to play a significant role in explaining the cross-sectional variation of management fees; hence, fund idiosyncratic volatility is not simply a proxy for size.

In Panel $\mathrm{C}$ we compute the average management fee across portfolios separated by both idiosyncratic volatility and level of portfolio turnover. Chalmers, Edelen, and Kadlec (1999) document that portfolio turnover constitutes the largest portion of total trading costs of mutual funds. If fund managers are overconfident about their ability to outperform the market, they may trade too much (Odean, 1999, and Barber and Odean, 2001) and increase the extent of portfolio rebalancing, which would tend to increase management fees. If trading costs induce higher management fees, we should observe a positive and significant relationship between fees and turnover, even after controlling for the level of idiosyncratic volatility. This is the result indicated in Panel C. In particular, within each level of fund volatility, those funds with higher active costs will require higher compensation. Similarly, for each level of turnover, the differences in management fees between high and low idiosyncratic volatility portfolios are statistically significant (at the $1 \%$ level of significance). In addition, these differences are quite stable across all turnover quintiles.

In Panel D we control instead for the age of the fund since inception. The empirical evidence on the relationship between the years of operation of a fund and its cost structure is somewhat unclear (see also Tufano and Sevick, 1997). For example, one may argue that young funds should incur high incubation costs. On the other hand, if such funds belong to large families, then their start-up cost may be subsidized in order to quickly attract new investments. This would tend to reduce start-up costs and increase fund net performance. Our findings in Panel D indicate that fund age does not seem to be an important driver of fees. In fact, the cost structure of mutual funds remains fairly constant across funds with different age profiles, after unsystematic risk has been taken into account.

In summary, it appears that for the vast majority of funds, idiosyncratic volatility explains most of the hidden underlying dynamics in advisory compensation. In particular, fund fees seem to depend on unsystematic risk-taking but not on the age of the fund. Of the remaining fund characteristics, fund size and family size also exhibit a significant negative relationship with 
management fees, as a result of economies of scale and scope, while fund turnover causes fees to increase as a function of the intensity in portfolio rebalancing of the fund investment strategy.

\section{C.2. The relationship between fees, idiosyncratic risk, and performance}

In figure 3, we document the average management fee across percentiles of both idiosyncratic volatility and fund past performance. In each year, we sort both fund net realized return and fund idiosyncratic volatility and form percentiles on either of the two variables. For each of these portfolios, we then compute the average management fee in the next period (year). In the first subplot of Figure 3, our percentile ranking is based on fund idiosyncratic volatility. Similar to the findings of Table IV, V, and IX the graph illustrates that fees are positively related to past unsystematic risk. Although we are not controlling yet for fund characteristics, investors seem to pay monotonically higher fees to funds that engage in higher unsystematic risk-taking.

The second subplot, instead, shows the average idiosyncratic volatility across percentiles of past realized performance. There is a clear non-linear relation between fund choice of unsystematic risk and its prior performance ranking. Funds with poor performance seem to be slightly less diversified and more prone to leverage on unsystematic risk than funds with good performance. In the third subplot of Figure 3, we also compute the average management fee across performance percentiles. The actual and interpolated values of the price-performance relationship clearly highlight that management fees are a non-linear function of prior performance. The common explanation put forward in the literature for the negative relationship between management fee and performance for those funds in the bottom performance rankings is that these funds exploit the heterogeneity of investors' demand; therefore investors are strategically separated according to their elasticity to performance, with less responsive investors being charged a higher fee. We suggest that this U-shaped sensitivities of fees to performance could also derive from an over-determined system where the relationship between (i) idiosyncratic risk and performance (step I), and (ii) fees and idiosyncratic risk (step II), indirectly cause fees to appear as if they were U-shaped in performance percentiles (step III).

If the U-shaped sensitivity of fees to fund performance is simply an artifact, we should then be able to obtain the fee-performance relationship by linking step I and step II. In particular, we compute the average idiosyncratic volatility for each percentile of realized performance (step I). We then compute the average management fee for each percentile of idiosyncratic volatility (step II). To combine step I and step II, we then search recursively for the specific percentile of 
idiosyncratic volatility where the average idiosyncratic volatility, resulting from each ascending percentile of performance, falls into. The fee corresponding to each of these identified percentiles of idiosyncratic volatility will constitute what we denote as 'simulated' fee-performance relationship. It is 'simulated' because we back up the sensitivities of fees to performance starting from (i) idiosyncratic risk across percentiles of performance and, (ii) fees across percentiles of idiosyncratic risk, rather that directly from the average fees across percentiles of performance. Figure 4 illustrates this point more clearly. The solid line represents the simulated feeperformance relationship. The dotted line is instead the actual fee-performance relationship previously documented in the last subplot of Figure 3. The surprising similarity between these two curves suggests that fees do not seem to be set on the basis of fund past performance, but rather as a result of the level of idiosyncratic volatility in performance. We acknowledge that in deriving this relationship we have not considered the potential effect of different fund characteristics. Thus, in the remaining sections of the paper, we run multivariate regressions to control for fund-specific characteristics which could also impact on fees.

\section{C.3 Sensitivities of fees to idiosyncratic risk in a multivariate framework}

In this section, we examine the nature of the relationship between fees and idiosyncratic risk in a multivariate framework. In table X, we pool all the variables and run a Fama and MacBeth (1973) least-square regression. As a robustness check, we also use year-fixed effect and panelcorrected standard errors (Petersen, 2008) to account for cross-sectional correlation as well as for the time series autocorrelation within funds. We control for small funds (Small), and star funds (Star) and use untabulated dummy variables for share classes and investment objectives. The dependent variable is the level of fund management fee (expressed in percentage terms for obvious scale reasons). To compute our representative measure of idiosyncratic volatility and performance, we use the unconditional factor model of Carhart (1997). ${ }^{23}$ In each year, we also rank funds on the basis of their ascending level of idiosyncratic volatility and attribute them to quintile portfolios (Q.1 to $Q .5)$. A fund will receive a 1 if it falls into the lowest quintile by idiosyncratic risk $(Q .1)$, and zero otherwise. In order to control for non-linearity in the feeperformance sensitivities, we use the squared value of risk-adjusted returns in Columns (v) and (vi).

\footnotetext{
${ }^{23}$ In table X, we report our results for the CAPM, Fama and French (1993) risk-adjusted returns, and Sirri and Tufano (1998) fractional rankings of realized performance. Our findings do not change when other models are used; these findings can be easily obtained from the authors on request.
} 
We control for several fund characteristics which proved to influence the level of fees. Consistent with the results in Table IX, economies of scale apply to fees: management fee decreases in the size of the fund (coefficients are significantly stable in the range between - 0.6 and -0.7). The negative relationship, instead, between fees and size of the family, as proxied by the number of funds under the management of the fund advisor, indicates the existence of significant economies of scope (the size of the coefficients depends on the scale of the variable). As expected, portfolio turnover and fees are positively related, while the negative relationship between flows and management fees is indirectly reflecting the effect of economies of scale on fees. In fact, in an unreported result we separated funds along the two dimensions of size (logarithm of fund TNA) and net flows: After controlling for fund size, flows do not exert any effect on management fees.

The positive sensitivity of fees to idiosyncratic risk (10.7) is documented in Column (i). Funds with higher idiosyncratic risk are also those that charge higher than average management fees. In the current setting, one standard deviation increase in the level of fund idiosyncratic volatility will correspond to a $13 \mathrm{bp}$ increase in the level of management fees. Considering that the average fund TNA is $\$ 624$ million, this average increase in fees will translates into an additional \$801 thousand being paid by shareholders to their riskier fund advisors. Further, if fund total volatility is mostly driven by its unsystematic component, we would expect that when we do not isolate the idiosyncratic component in the regression, fund total volatility will inherit a positive estimated coefficient such as those documented in Columns (iii), and (v).

No significant relationship exists, instead, between fees and performance (Column (iii)). Since this result may arise from the non-linear relationship of fees in performance documented in Figure 3, in Column (v) we decided to include a squared performance variable (alpha_squared). The findings of Columns ( $\mathrm{v}$ ) of a U-shaped relationship between fees and performance are consistent with the evidence of Gruber (1996) Carhart (1997) Harless and Peterson (1998), Wermers, (2000; 2003), Barber, Odean, and Zheng (2005), Kuhnen (2005), Kosowski et al (2006), and Gil-Bazo and Ruiz-Verdu (2009). The coefficient of the squared alpha is positive and significant, giving the impression that fees may react differently to different performance rankings. However, when we control for the monotonically positive relationship between fees and $\sigma(\varepsilon)$ in Column (vi), idiosyncratic volatility seems to entirely capture the non-linear sensitivities of fee to performance. Indeed, the coefficient of the variable alpha_squared is now insignificant.

In Columns (vii) and (viii), we document the sensitivity of fees to idiosyncratic volatility, for increasing levels of this volatility. After controlling for common fund characteristics, the 
gradually greater the extent of idiosyncratic risk-taking of a fund, the monotonically higher the management fees charged to investors.

\section{C.4 The impact of idiosyncratic volatility on the fee-performance relationship}

Table XI reports the results of a battery of tests to quantify the effect of fund risk-taking on the empirical relationship between fees and fund performance rankings. The aim is to try to establish the relevance of the fee-performance relationship and the rationale behind mutual fund fee setting. In Column (i) and (ii), we separate fund performance in terciles by using the dummy variables of Mid (tercile 2) and High (tercile 3) performance. In this way, we aim to capture the change in the loadings of fees on different performance rankings with and without controlling for fund idiosyncratic volatility. In particular, it appears that underperforming mutual funds seem to charge - on average - higher fees as previously indicated by Gil-Bazo and Ruiz-Verdu (2009). The effect of the introduction of idiosyncratic volatility in Column (ii) is to halve the sensitivities documented in Column (i) of fees to performance rankings. Moreover, if fee-setting is driven by idiosyncratic risk rather than performance, we should expect that when we interact fund performance with the level of idiosyncratic risk $($ alpha* $\sigma(\varepsilon))$, the interaction term would absorb the impact of (under-)performance on fees. Indeed, the introduction of the interaction term in Column (iii) cause the significantly negative relationship between fees and performance $(-0.614)$ illustrated in Column (ii) to disappear. This negative coefficient is now completely transferred to the interaction term (-0.446) in Column (iii), leaving an inelastic fee for poor performing funds performance. As a result, the effect of performance on fees is now entirely modulated by the level of idiosyncratic risk. For overperforming funds, instead, the relationship is positive and significant even after controlling for unsystematic risk. ${ }^{24}$

The hypothesis of mutual fund strategic fee-setting advocated in the literature implies that the negative relationship between fees and poor performance arises as a result of underperforming funds charging higher fees to their unsophisticated investors. We posit that for this explanation to undoubtedly justify the underlying dynamics of fees we should find that the negative feeperformance relationship disappears if we restrict the coefficient estimations only to those funds that left unchanged their fees. The existence of a negative relationship for funds that left their fees constant would obviously cast doubts on the plausibility of the strategic fee-setting proposition based exclusively on fund performance. The findings of this test are reported in Columns (iv) and

\footnotetext{
${ }^{24}$ Our results remain unchanged when we estimated the multivariate regression using year- or fund- fixed effects and clustering of standard errors at fund, time, and fund and time.
} 
(v) of table XI, where we estimate the price-performance relationship only for those 4,766 fundyear observations where there is no change in fees. It is evident at this point that even in presence of constant fees we can still observe a negative relationship between fees and performance. After controlling for $\sigma(\varepsilon)$ in Column (v), the negative fee-performance sensitivity becomes insignificant. Gil-Bazo and Ruiz-Verdu (2009) suggested - but did not test for - the possibility that their findings be also governed by “...unobserved fund characteristics" which are indirectly correlated with management fees. We show in table XI that this is indeed the case; the indirect role is played by the higher price requested by high risk-taking funds to their shareholders.

\section{C.5 Robustness to different risk and performance measures}

As a robustness check, in Table XII we re-estimate the sensitivities of fees using different measures of performance and idiosyncratic volatility. In particular, we used the CAPM in Column (i), the Fama and French (1993) model in Column (ii), the net raw realized performance in Column (iii), and the Sirri and Tufano (1998) fractional rankings of performance in Columns from (iv) to (vii). Our conclusions are robust: fees are an increasing function of fund idiosyncratic volatility. Regardless of the performance measure used, fees do not respond to performance after isolating the effect of unsystematic risk on fee sensitivities. ${ }^{25}$ In Columns from (iii) to (vii) we use as a proxy for idiosyncratic risk-taking the standard deviation of the residuals from the Carhart (1997) factor model. The findings of Column (iv) and (v) echo those of Table XI: when we use piecewise performance rankings based on realized performance to account for the nonlinearity of fees in fund performance, a clear U-shaped relationship arises. Nevertheless, after controlling for idiosyncratic risk-taking the significant elasticities of price to performance for funds at the extreme of the performance distribution completely vanish. In Column (vi) and (vii) we repeated instead the estimation of the model in Column (v) in the two subperiods from 1994 to 1999 (Column (vi)) and from 2000 to 2007 (Column (vii)). Our conclusion remains unaffected.

\section{Conclusion}

This paper makes a significant contribution to the mutual fund literature by emphasizing for the first time the implications of idiosyncratic risk for fund performance evaluation, advisory feesetting, and investors' performance chasing behavior. In particular, we show that not only do high

${ }^{25}$ In columns (i) and (ii) our measure of idiosyncratic volatility is that of the CAPM and Fama and French (1993) model, respectively. 
idiosyncratic risk funds populate the tails of the performance distribution but they are also (and more importantly) characterized by higher probability of transitioning into the tails of the performance distribution. These transition probabilities cause funds with higher idiosyncratic risk to oscillate relatively more frequently from one extreme to the other of the performance distribution. By swinging relatively more often back and forth along the "performance pendulum", high idiosyncratic risk funds stretch the cross section of realized and risk-adjusted performance, and therefore reduce fund performance persistence. The implication is that they might eclipse investors' precision of the prior, with respect to the level of skills of their fund managers.

If shareholders use performance primarily to infer managerial skills and efforts, then when fund performance is mostly driven by noise, we would expect the flow-performance sensitivity to diminish as a result of the greater uncertainty surrounding performance. We show that this is indeed the case. In particular, we demonstrate that investors become progressively more insensitive to performance for those funds engaging in more idiosyncratic risk-taking. Accordingly, a significantly negative relationship exists between estimated flow-performance sensitivity and fund idiosyncratic volatility.

We also document that funds with high idiosyncratic risk are relatively small, on average, engage in more aggressive investment strategies, and that their portfolios are mostly concentrated in small stocks and in growth stocks. Since they are smaller in size, one might expect that such funds should also experience higher costs per dollar under management. We indicate that the aggressiveness of their investment objectives imposes more frequent portfolio rebalancing, which explains, to some extent, the higher fees charged by high idiosyncratic volatility funds. Thus, funds with higher idiosyncratic risk are also more expensive investment vehicles.

Finally, we demonstrate that the previously-documented anomalous relationship between fund fees and performance is irrelevant and does not survive after controlling for the pervasive effect exerted by idiosyncratic risk on performance persistence and fees. An important consequence is that after properly controlling for the level of idiosyncratic risk of a fund, the fee-performance relationship does not necessarily require any explanation involving strategic behavior on the part of fund managers or a lack of sophistication on the part of investors.

\section{References}

Ang, A., R. Hodrick, Y. Xing, and X. Zhang, 2006. The cross-section of volatility and expected returns. Journal of Finance, 61: 259-299. 
Ang, A., R. Hodrick, Y. Xing, and X. Zhang, 2009. High idiosyncratic volatility and low returns,: International and further U.S. evidence, Journal of Financial Economics, 91: 1-23.

Avramov, D. and R. Wermers, 2006. Investing in mutual funds when returns are predictable, Journal of Financial Economics, 81, 339-377.

Barber, B. M., and T. Odean, 2001. Boys will be Boys: Gender, Overconfidence, and Common Stock Investment, Quarterly Journal of Economics, 116(1): 261-292.

Barber, B. M., T. Odean and L. Zheng, 2005. Out of sight, out of mind: the effects of expenses on mutual fund flows. Journal of Business, 78: 2095-2120.

Barras, L, O. Scaillet, R. Wermers, 2010. False discoveries in mutual fund performance: Measuring luck in estimated alphas, Journal of Finance, 65: 179-216.

Berk, J. B. and R.C. Green., 2004. Mutual fund flows and performance in rational markets, Journal of Political Economy, 112(6): 1269-1295.

Berk, J. B. and I. Tonks, 2007. Return persistence and fund flows in the worst performing mutual funds, Working Paper.

Bollen, N. P. B. and J. A. Busse, 2001. On the timing ability of mutual fund managers. Journal of Finance 56, 1075-1094.

Bollen, N.P.B, and Busse, J.A., 2005. Short-term persistence in mutual fund performance, Review of Financial Studies, 18(2): 569-597.

Brown, S. J. and W. N. Goetzmann, 1995. Performance persistence. Journal of Finance, 50: 853-873.

Brown, S. J. and W. N. Goetzmann, 1997. Mutual fund styles. Journal of Financial Economics, 43: 373399.

Brown, K.C., W. V. Harlow, and H. Zhang, 2009. Staying the course: The role of investment style consistency in the performance of mutual funds. Working Paper, University of Texas at Austin.

Brown, K.C., W. V. Harlow, and L.T. Starks, 1996. Of tournaments and temptations: An analysis of managerial incentives in the mutual fund industry, Journal of Finance 51: 85-110.

Chalmers, J.M., R.M. Edelen, and G.B. Kadlec, 1999. An analysis of mutual fund trading costs. University of Oregon, University of Pennsylvania.

Campbell, J.Y., M. Lettau, B.G. Malkiel, and Y. Xu, 2001. Have individual stocks become more volatile? An empirical exploration of idiosyncratic risk. Journal of Finance. 56: 1-44.

Carhart, M.M., 1997. On persistence in mutual fund performance, Journal of Finance 52: 57-82.

Chan, L.K.C., H. Chen, and J. Lakonishok, 2002. On mutual fund investment styles. Review of Financial Studies, 15: 1407-1437.

Chen, J., H. Hong, M. Huang, and J.D. Kubik, 2004. Does fund size erode mutual fund performance? The role of liquidity and organization, American Economic Review, 94(5): 1276-1302.

Chevalier, J. and G. Ellison (1997). Risk taking by mutual funds as a response to incentives. Journal of Political Economy 105 (6): 1167-1200.

Christoffersen, S. and D. Musto, 2002. Demand curves and the pricing of money management, Review of Financial Studies 15: 1499-1524.

Cremers, M., A. Petajisto, and E. Zitzewitz, 2008. Should benchmark indices have alpha? Revisiting performance evaluation, Working Paper, Yale University.

Cremers, M., and A. Petajisto, 2009. How active is your fund manager? A new measure that predicts performance. Review of Financial Studies, 22 (9): 3329-3365.

Daniel, K., M. Grinblatt, S. Titman, and R. Wermers, 1997. Measuring Mutual Fund Performance with Characteristic-Based Benchmarks, Journal of Finance, 52 (3): 1035-1058. 
DelGuercio, D. and P. A. Tkac (2002). The determinants of the flow of funds of managed portfolios: Mutual funds versus pension funds. Journal of Financial and Quantitative Analysis 37, 523-557.

Deli, D.N. 2002. Mutual fund advisory contracts: An empirical investigation. Journal of Finance. 57(1): 109-133.

Elton, E. M.J. Gruber, and C.R. Blake, 1996. The persistence of risk-adjusted mutual fund performance, Journal of Business 69: 133-157.

Elton, E. M.J. Gruber, and C.R. Blake, 2001. A first look at the accuracy of CRSP mutual fund database and a comparison of the CRSP and Morningstar mutual fund databases, Journal of Finance 56: 24152430 .

Elton, E. M.J. Gruber, and C.R. Blake, 2003. Incentives and mutual funds, Journal of Finance 58: 779-804.

Elton, E.J., M.J. Gruber, S. Das, and M. Hlavka, 1993. Efficiency with costly information: a reinterpretation of evidence from managed portfolios, Review of Financial Studies, 6: 1-22.

Evans, R. B., 2009. Mutual fund incubation, Journal of Finance, Forthcoming.

Falkenstein, E.G., 1996. Preferences for Stock Characteristics as Revealed by Mutual Fund Portfolio Holdings, Journal of Finance, 51: 111-135.

Fama, E. and K. French, 1993. Common risk factors in the returns on stocks and bonds, Journal of Financial Economics 33: 3-56.

Fama, E. and K. French, 2010. Luck versus skill in the cross section of mutual fund returns, Journal of Finance forthcoming.

Fama, E. and J. MacBeth, 1973. Risk, return and equilibrium: Empirical tests, Journal of Political Economy 81: 607-636.

French, K.R., W. Schwert, and R.F. Stambaugh, 1987. Expected stock returns and volatility, Journal of Financial Economics 19, 3-29.

Ferson, W. E. and Schadt, R. W., 1996. Measuring fund strategy and performance in changing economic conditions, Journal of Finance, 61: 73-104.

Gil-Bazo, J. and P. Ruiz-Verdu, 2008. When cheaper is better: Fee determination in the market for equity mutual funds, Journal of Economic Behavior \& Organization, 67: 871-885.

Gil-Bazo, J. and P. Ruiz-Verdu, 2009. The Relation between Price and Performance in the Mutual Fund Industry, Journal of Finance (forthcoming).

Goetzmann, W.N and R., Ibbotson, 1994. Do winners repeat? Patterns in mutual fund behavior. Journal of Portfolio Management, 20: 9-18.

Goetzmann, W.N. and N. Peles, 1997. Cognitive dissonance and mutual fund investors. Journal of Financial Research, 20 (2): 145-158.

Golec, J.H., 1992. Empirical tests of a principal-agent model of the investor-investment advisor relationship, Journal of Financial and Quantitative Analysis, 27: 81-95.

Goyal, A. and P. Santa-Clara, 2003. Idiosyncratic risk matters!, Journal of Finance, 58: 975-1007.

Grinblatt, M. and S. Titman, 1992. The persistence of mutual fund performance. Journal of Finance 47: 1977-1984.

Gruber, M., 1996. Another puzzle: The growth in actively managed mutual funds, Journal of Finance 52: 783-810.

Harless, D.W. and Peterson, S. P., 1998. Investor behavior and the persistence of poorly-performing mutual funds, Journal of Economic Behavior \& Organization, 37: 257-276.

Heaton, J., and D.J. Lucas, 1996. Evaluating the effects of incomplete markets on risk sharing and asset pricing, Journal of Political Economy, 104(3): 443-487. 
Heinkel, R., and N.M. Stoughton, 1994. The dynamics of portfolio management contracts. Review of Financial Studies, 7: 351-388.

Hendricks, D., Patel, J., and Zeckhauser, R., 1993. Hot hands in mutual funds: short-run persistence of relative performance, Journal of Finance 48: 93-130.

Huang, J., K.D. Wei, and H. Yan, 2007. Participation costs and the sensitivity of fund flows to past performance, Journal of Finance 62: 1273-1311.

Huang, J., C. Sialm, and H. Zhang, 2009. Risk shifting and mutual fund performance, Working paper. Univeristy of Texas at Austin.

Huij, J. and M. Verbeek, 2007. On the use of multi-factor models to evaluate mutual fund performance. Working Paper. Erasmus University.

Ippolito, R. A. (1992). Consumer reaction to measures of poor quality: Evidence from the mutual fund industry. Journal of Law and Economics 35 (1): 45-70.

Jegadeesh, N. and S. Titman, 1993. Returns to buying winners and selling losers: Implications for stock market efficiency, Journal of Finance 48: 65-91.

Kacperczyk, M, C. Sialm, and L. Zheng, 2005. On the industry concentration of actively managed equity mutual funds, Journal of Finance, 60: 1983-2011.

Khorana, A., H. Servaes, and P.Tufano, 2008. Mutual fund fees around the world. Review of Financial Studies. 22(3): 1279-1310.

Kosowski, R., A. Timmermann, R. Wermers and H. White, 2006. Can mutual fund stars" really pick stocks? New evidence from a bootstrap analysis, Journal of Finance, 61: 2551-2595.

Kostovetsky, L., 2008. Brain drain: Are mutual funds losing their best minds?, Working Paper, University of Rochester.

Kuhnen, C.M. 2005. Dynamic contracting in the mutual fund industry, Working paper, Northwestern University.

Lakonishok, J, A. Shleifer, and R.W. Vishny, 1992. The Structure and Performance of the Money Management Industry, Brookings Papers on Economic Activity: Microeconomics, 339-391.

Lehmann, B.N. and D.M. Modest, 1988. The empirical foundations of the arbitrage pricing theory. Journal of Financial Economics. 21 (2): 213-254.

Lucas, D.J., 1994. Asset pricing with undiversifiable income risk and short sales constraints: Deepening the equity premium puzzle, Journal of Monetary Economics, 34(3): 325-341.

Lynch, A.W. and Musto, D.K., 2003. How investors interpret past returns, Journal of Finance, 58: 20332058.

Malkiel, B.G., 1995. Returns from investing in equity mutual funds 1971-1991, Journal of Finance, 50: 549-572.

Malkiel, B.G. and Y. Xu, 2006. Idiosyncratic risk and security returns, Working paper, University of Texas at Dallas.

Mamaysky, H., M. Spiegel and H. Zhang, 2007. Improved forecasting of mutual fund alphas and betas. Review of Finance, (August): 1:42

Mamaysky, H., M. Spiegel and H. Zhang, 2008. Estimating the dynamics of mutual fund alphas and betas. Review of Financial Studies, 21 (1): 1:42

Massa, M. and R. Patgiri, 2009. Incentives and mutual fund performance: Higher performance or just higher risk taking? Review of Financial Studies, 22(5): 1777-1815.

Merton, R.C., 1987. A simple model of capital market equilibrium with incomplete information, Journal of Finance, 42: 483-510. 
Nanda, V., Z. J. Wang, and L. Zheng, 2004. Family values and the star phenomenon: Strategies of mutual fund families. Review of Financial Studies, 17(3), 667-698.

Newey, W. and K. West, 1987. A simple positive definite heteroscedasticity and autocorrelation consistent covariance matrix. Econometrica 55, 703-705.

Odean, T., 1999. Do Investors Trade Too Much? American Economic Review, 89: 1279-1298.

Pastor, L. and R. F. Stambaugh, 2003. Liquidity risk and expected stock returns. Journal of Political Economy, 111(3): 642-685.

Petersen, M.A., 2009. Estimating standard errors in finance panel data sets: Comparing approaches, Review of Financial Studies, 22, 435-480.

Sadka, R., 2006. Momentum and post-earnings-announcement drift anomalies: The role of liquidity risk. Journal of Financial Economics, 80: 309-349.

Shukla, R.K., and C.A. Trzcinka, 1992. Performance measurement of managed portfolios, Financial Markets, Institutions \& Instruments, 1(4), 1-58.

Sirri, E. and P. Tufano, 1998. Costly search and mutual fund flows, Journal of Finance 53: 1589-1622.

Teo, M. and S. Woo, 2001. Persistence in style-adjusted mutual fund returns. Working Paper, Harvard University.

Tufano, P. and M. Sevick, 1997. Board structure and fee-setting in the U.S. mutual fund industry, Journal of Financial Economics 46: 321-355.

Warner, J.B. and J.S. Wu, 2006. Why do mutual fund advisory contract change? Fund versus family influences. Working Paper. University of Rochester.

Wermers, R., 1999. Mutual fund herding and the impact on stock prices. Journal of Finance 54: 581-622.

Wermers, R., 2000. Mutual fund performance: An empirical decomposition into stock-picking talent, style, transaction costs, and expenses, Journal of Finance 55: 1655-1703.

Wermers, R., 2003. Is money really "smart"? New evidence on the relation between mutual fund flows, manager behavior, and performance persistence, University of Maryland, Working Paper.

Zheng, L. 1999. Is money smart? A study of mutual fund investors' fund selection ability." Journal of Finance 54: 901-33. 


\section{Table I}

\section{Summary Statistics}

This table reports the summary statistics of our sample of diversified US equity mutual funds from 1994 to 2007 . Panel A reports the descriptive statistics of the following fund characteristics: yearly net money flow rate, total net asset (TNA) of both fund and family of funds, logarithm of fund age (since inception), average number of funds in a family, fund portfolio turnover, management fees (operating expenses minus 12B-1 fees), operating expense ratios, Carhart (1997) four-factor after-fee returns (alpha), fund idiosyncratic volatility (denoted as $\sigma(\varepsilon))$ of the four-factor model, reported after-fee returns, and volatility of previous 12-month raw returns. Panel B, instead, documents the statistics of annual management fees as well as the frequencies and extent of their yearly variations $(\Delta f)$.

\begin{tabular}{lcccccccc}
\hline \multirow{2}{*}{ Panel A } & \multirow{2}{*}{ Obs. } & \multirow{2}{*}{ Mean } & Standard & \multicolumn{5}{c}{ Percentiles } \\
\cline { 7 - 9 } & & & Deviation & $1 \%$ & $25 \%$ & $50 \%$ & $75 \%$ & $99 \%$ \\
\hline Net Flows (\%) & 41,360 & $15.8 \%$ & $54.4 \%$ & $-57.0 \%$ & $-14.7 \%$ & $0.5 \%$ & $28.9 \%$ & $232.8 \%$ \\
TNA (in \$m) & 42,177 & 624.0 & 3086.6 & 0.1 & 11.5 & 56.7 & 268.3 & 10322.9 \\
log fund Age & 42,096 & 1.92 & 0.84 & 0.46 & 1.32 & 1.87 & 2.40 & 4.14 \\
TNA Family (in \$m) & 43,669 & $19,962.0$ & $68,501.3$ & 0.0 & 0.0 & 963.6 & $9,897.4$ & $423,424.8$ \\
N.Fund Family & 43,669 & 22.84 & 28.67 & 1.00 & 1.00 & 10.00 & 36.00 & 135.00 \\
Turnover & 41,269 & 0.97 & 1.36 & 0.02 & 0.38 & 0.70 & 1.18 & 5.04 \\
Management fee & 43,487 & $1.14 \%$ & $0.41 \%$ & $0.08 \%$ & $0.91 \%$ & $1.11 \%$ & $1.32 \%$ & $2.50 \%$ \\
Opex & 43,487 & $1.62 \%$ & $0.57 \%$ & $0.25 \%$ & $1.20 \%$ & $1.57 \%$ & $2.02 \%$ & $3.05 \%$ \\
Carhart alpha (af) & 29,656 & $-1.36 \%$ & $5.43 \%$ & $-15.81 \%$ & $-3.87 \%$ & $-1.42 \%$ & $1.08 \%$ & $14.24 \%$ \\
o(́) & 29,656 & $1.57 \%$ & $1.18 \%$ & $0.37 \%$ & $0.88 \%$ & $1.26 \%$ & $1.89 \%$ & $6.61 \%$ \\
Returns (af) & 42,095 & $8.96 \%$ & $20.57 \%$ & $-42.32 \%$ & $-0.90 \%$ & $9.87 \%$ & $19.69 \%$ & $64.76 \%$ \\
Volatility & 42,095 & $4.33 \%$ & $2.33 \%$ & $1.15 \%$ & $2.76 \%$ & $3.81 \%$ & $5.36 \%$ & $12.87 \%$ \\
\hline
\end{tabular}


Table II

Analysis of the Persistence and Characteristics of the Portfolios Sorted on Past Performance

In this table, at the end of each calendar year (December $31^{\text {st }}$ ) from 1994 to 2007 we sort our sample of mutual funds on their unconditional four-factor model alphas (the intercept of the model). For a fund to be in our sample we require at least 36 months of consecutive observations. We then separate the sorted funds in ten portfolios (deciles) which are equally-weighted so that the portfolio weights are re-adjusted whenever a fund disappears from the sample. Decile 1 (10) comprises funds with the highest (lowest) value of the past three-year alphas. For each portfolio, we then compute over the following year the monthly average of the portfolio after-fee excess return $(E R)$, standard deviation, Alpha, absolute value of the Newey-West t-statistic for the unconditional four-factor model alpha, one-tailed Newey-West (1987) parametric p-value of the alpha, the cross-sectionally bootstrapped p-values of the unconditional $t$-statistics of the alpha, mean and standard deviation of the residuals. $R M R F, S M B$, and $H M L$ are the Fama and French's (1993) factor-mimicking portfolios for size and book-to-market of equity. PRIYR is the Jegadeesh and Titman (1993) factor-mimicking portfolio for the 1-year return momentum. PS liquidity is the Pastor and Stambaugh (2003) liquidity innovation factor mimicking portfolio. We also include in the table the statistics obtained for other percentiles of the distribution and for the top and bottom 5 stocks in the ranking.

\begin{tabular}{|c|c|c|c|c|c|c|c|c|c|c|c|c|c|c|}
\hline $\begin{array}{l}\text { Performance } \\
\text { Fractiles }\end{array}$ & $\begin{array}{c}\text { ER } \\
\text { (p.m.) }\end{array}$ & $\begin{array}{c}\text { Std Dev } \\
\text { (p.m.) }\end{array}$ & alpha (p.m.) & $\operatorname{se}(\alpha)($ p.m. $)$ & $\begin{array}{c}\text { Robust N-W } t \\
\text { stat }(\alpha)\end{array}$ & $\begin{array}{l}\text { Parametric } p- \\
\quad \text { value }(\alpha)\end{array}$ & $\begin{array}{c}\text { Bootstr. p- } \\
\text { val }(\mathrm{t}[\alpha]) \\
\text { (Right tail) }\end{array}$ & $\begin{array}{c}\mu(\varepsilon) \\
\text { (Pre-form) }\end{array}$ & $\begin{array}{c}\sigma(\varepsilon) \text { (Pre- } \\
\text { form) }\end{array}$ & RMRF & SMB & HML & PR1YR & Adj $R^{2}$ \\
\hline & (i) & (ii) & (iii) & (iv) & (v) & (vi) & (vii) & (xiii) & (xiv) & (viii) & (ix) & (x) & (xi) & (xii) \\
\hline Top & $-0.15 \%$ & $5.37 \%$ & $2.47 \%$ & $1.05 \%$ & 2.36 & 0.04 & 0.11 & $0.00 \%$ & $4.38 \%$ & 0.64 & 0.49 & -0.92 & 0.10 & $56.0 \%$ \\
\hline 2nd Best & $0.12 \%$ & $5.65 \%$ & $1.47 \%$ & $0.70 \%$ & 2.11 & 0.01 & 0.03 & $0.00 \%$ & $3.80 \%$ & 0.97 & 0.48 & -0.70 & 0.00 & $69.9 \%$ \\
\hline 3rd Best & $-0.35 \%$ & $5.22 \%$ & $1.27 \%$ & $0.71 \%$ & 1.79 & 0.04 & 0.10 & $0.00 \%$ & $3.42 \%$ & 1.02 & 0.58 & -0.09 & 0.02 & $57.7 \%$ \\
\hline 4th Best & $-0.77 \%$ & $6.90 \%$ & $0.95 \%$ & $0.78 \%$ & 1.21 & 0.04 & 0.11 & $0.00 \%$ & $4.89 \%$ & 0.91 & 0.64 & -0.86 & 0.02 & $73.0 \%$ \\
\hline 5th Best & $-1.05 \%$ & $5.14 \%$ & $0.82 \%$ & $0.71 \%$ & 1.15 & 0.05 & 0.12 & $0.00 \%$ & $4.07 \%$ & 1.04 & 0.50 & -0.24 & 0.21 & $74.3 \%$ \\
\hline $3 \%$ ile & $-0.19 \%$ & $3.94 \%$ & $0.59 \%$ & $0.48 \%$ & 1.23 & 0.07 & 0.14 & $0.00 \%$ & $3.16 \%$ & 0.89 & 0.42 & -0.23 & 0.05 & $78.9 \%$ \\
\hline $5 \%$ ile & $-0.14 \%$ & $3.64 \%$ & $0.50 \%$ & $0.41 \%$ & 1.23 & 0.08 & 0.20 & $0.00 \%$ & $2.59 \%$ & 0.91 & 0.35 & -0.20 & 0.02 & $79.6 \%$ \\
\hline 1.Dec & $-0.17 \%$ & $3.26 \%$ & $0.39 \%$ & $0.35 \%$ & 1.11 & 0.12 & 0.19 & $0.00 \%$ & $2.09 \%$ & 0.91 & 0.33 & -0.13 & 0.01 & $82.1 \%$ \\
\hline 2.Dec & $-0.12 \%$ & $2.39 \%$ & $0.14 \%$ & $0.24 \%$ & 0.59 & 0.30 & 0.67 & $0.00 \%$ & $1.42 \%$ & 0.93 & 0.20 & 0.00 & 0.01 & $86.4 \%$ \\
\hline 3.Dec & $-0.11 \%$ & $1.87 \%$ & $0.03 \%$ & $0.21 \%$ & 0.13 & 0.45 & 0.27 & $0.00 \%$ & $1.26 \%$ & 0.92 & 0.11 & 0.05 & 0.00 & $87.6 \%$ \\
\hline 4.Dec & $-0.15 \%$ & $1.88 \%$ & $-0.04 \%$ & $0.20 \%$ & -0.22 & 0.60 & 0.18 & $0.00 \%$ & $1.18 \%$ & 0.93 & 0.10 & 0.07 & 0.00 & $88.9 \%$ \\
\hline 5.Dec & $-0.14 \%$ & $1.84 \%$ & $-0.11 \%$ & $0.22 \%$ & -0.51 & 0.72 & 0.07 & $0.00 \%$ & $1.25 \%$ & 0.96 & 0.12 & 0.06 & 0.01 & $88.9 \%$ \\
\hline 6.Dec & $-0.22 \%$ & $1.92 \%$ & $-0.14 \%$ & $0.20 \%$ & -0.71 & 0.79 & $<0.01$ & $0.00 \%$ & $1.22 \%$ & 0.95 & 0.11 & 0.02 & 0.02 & $88.4 \%$ \\
\hline 7.Dec & $-0.23 \%$ & $2.10 \%$ & $-0.23 \%$ & $0.22 \%$ & -1.05 & 0.88 & $<0.01$ & $0.00 \%$ & $1.28 \%$ & 0.97 & 0.13 & 0.01 & 0.02 & $89.3 \%$ \\
\hline 8.Dec & $-0.17 \%$ & $2.18 \%$ & $-0.30 \%$ & $0.25 \%$ & -1.19 & 0.92 & $<0.01$ & $0.00 \%$ & $1.45 \%$ & 0.98 & 0.16 & 0.01 & 0.03 & $89.3 \%$ \\
\hline 9.Dec & $-0.14 \%$ & $2.20 \%$ & $-0.42 \%$ & $0.28 \%$ & -1.52 & 0.95 & $<0.01$ & $0.00 \%$ & $1.66 \%$ & 1.00 & 0.19 & -0.01 & 0.06 & $87.2 \%$ \\
\hline 10.Dec & $-0.10 \%$ & $2.97 \%$ & $-0.86 \%$ & $0.42 \%$ & -2.08 & 0.97 & $<0.01$ & $0.00 \%$ & $2.63 \%$ & 1.03 & 0.45 & -0.01 & 0.09 & $80.8 \%$ \\
\hline $95 \%$ ile & $-0.09 \%$ & $3.46 \%$ & $-1.11 \%$ & $0.47 \%$ & -2.36 & 0.98 & $<0.01$ & $0.00 \%$ & $3.14 \%$ & 1.02 & 0.50 & 0.00 & 0.07 & $77.7 \%$ \\
\hline $97 \%$ ile & $-0.28 \%$ & $3.83 \%$ & $-1.26 \%$ & $0.51 \%$ & -2.46 & 0.98 & $<0.01$ & $0.00 \%$ & $3.40 \%$ & 1.02 & 0.54 & -0.02 & 0.07 & $76.0 \%$ \\
\hline 5th Worst & $-0.68 \%$ & $3.82 \%$ & $-2.00 \%$ & $0.57 \%$ & -3.54 & 1.00 & $<0.01$ & $0.00 \%$ & $3.83 \%$ & 1.18 & 0.33 & -0.22 & -0.10 & $67.0 \%$ \\
\hline 4th Worst & $-1.17 \%$ & $7.79 \%$ & $-2.19 \%$ & $0.98 \%$ & -2.25 & 0.99 & $<0.01$ & $0.00 \%$ & $6.18 \%$ & 0.89 & 0.78 & -0.05 & 0.04 & $50.9 \%$ \\
\hline 3rd Worst & $-0.22 \%$ & $6.22 \%$ & $-2.17 \%$ & $1.08 \%$ & -2.00 & 0.99 & 0.02 & $0.00 \%$ & $5.49 \%$ & 1.01 & 0.64 & -0.04 & 0.20 & $34.9 \%$ \\
\hline 2nd Worst & $-1.66 \%$ & $5.53 \%$ & $-3.17 \%$ & $0.70 \%$ & -4.54 & 1.00 & $<0.01$ & $0.00 \%$ & $5.10 \%$ & 1.15 & 0.56 & -0.25 & 0.20 & $55.2 \%$ \\
\hline Worst & $-2.63 \%$ & $7.76 \%$ & $-4.12 \%$ & $1.32 \%$ & -3.12 & 1.00 & $<0.01$ & $0.00 \%$ & $8.79 \%$ & 0.89 & 0.33 & -0.34 & 0.10 & $28.3 \%$ \\
\hline 1st-10th decile & -0.001 & $0.29 \%$ & $1.26 \%$ & $-0.06 \%$ & & & & $0.00 \%$ & $-0.55 \%$ & -0.12 & -0.12 & -0.12 & -0.07 & $1.35 \%$ \\
\hline 5th- 95th pctile & -0.001 & $0.18 \%$ & $1.61 \%$ & $-0.06 \%$ & & & & $0.00 \%$ & $-0.55 \%$ & -0.11 & -0.14 & -0.20 & -0.05 & $1.89 \%$ \\
\hline
\end{tabular}


Table III

Transition Probabilities of Performance

Conditional on the Level of Fund Idiosyncratic Volatility

The table documents inter-tercile transition probabilities (in percentage) of fund realized raw returns conditional on the level of their idiosyncratic volatility $(\sigma(\varepsilon))$. In each year, we first rank funds based on their $\sigma(\varepsilon)$ and attribute them to ten portfolios (deciles). Decile 1 (10) is characterized by funds with the lowest (highest) level of $\sigma(\varepsilon)$. We then separate fund annual realized performance in terciles (T), with tercile 1 (3) comprising those funds with the worst (best) yearly performance. The sample is subsequently divided in 9 groups based on the annual inter-tercile performance transition. Therefore, a fund moving from the lowest (highest) to the highest (lowest) tercile is indicated with $T_{1, t-1}-T_{3, t}\left(T_{3, t-1}\right.$ $T_{1, t}$ ). Finally, we compute the fund transition probabilities within each decile of idiosyncratic volatility. We also document the number of funds that populate each decile.

\begin{tabular}{lcccccccccc}
\hline & \multicolumn{7}{c}{ Panel A. Performance transition probabilities (in pct from year $t-1$ to year $t$ ) } \\
\cline { 2 - 10 } $\begin{array}{l}\text { Deciles of } \\
\sigma\left(\varepsilon_{i}\right)\end{array}$ & Obs. & $\mathrm{T}_{1, t-1}-\mathrm{T}_{1, t}$ & $\mathrm{~T}_{1, t-1}-\mathrm{T}_{2, t}$ & $\mathrm{~T}_{1, t-1}-\mathrm{T}_{3, t}$ & $\mathrm{~T}_{2, t-1}-\mathrm{T}_{l, t}$ & $\mathrm{~T}_{2, t-1}-\mathrm{T}_{2, t}$ & $\mathrm{~T}_{2, t-1}-\mathrm{T}_{3, t}$ & $\mathrm{~T}_{3, t-1}-\mathrm{T}_{1, t}$ & $\mathrm{~T}_{3, t-1}-\mathrm{T}_{2, t}$ & $\mathrm{~T}_{3, t-1}-\mathrm{T}_{3, t}$ \\
\cline { 2 - 11 } & & (i) & (ii) & (iii) & (iv) & (v) & (vi) & (vii) & (viii) & (ix) \\
\hline Dec. 1 & 3261 & 9.41 & 13.03 & 3.77 & 14.19 & 31.18 & 7.11 & 4.69 & 8.43 & 8.19 \\
Dec. 2 & 3257 & 12.80 & 11.18 & 4.21 & 14.06 & 22.08 & 9.89 & 5.43 & 11.67 & 8.69 \\
Dec. 3 & 3263 & 14.47 & 10.09 & 6.41 & 12.75 & 17.96 & 11.01 & 6.65 & 9.96 & 10.70 \\
Dec. 4 & 3257 & 14.37 & 9.92 & 6.75 & 12.19 & 13.79 & 11.08 & 6.54 & 11.15 & 14.22 \\
Dec. 5 & 3261 & 13.58 & 8.80 & 7.02 & 9.01 & 13.24 & 10.73 & 9.04 & 12.07 & 16.52 \\
Dec. 6 & 3259 & 12.92 & 9.42 & 9.73 & 10.56 & 9.63 & 10.52 & 8.41 & 10.65 & 18.17 \\
Dec. 7 & 3258 & 13.57 & 9.18 & 9.64 & 10.68 & 8.75 & 10.59 & 10.68 & 8.66 & 18.26 \\
Dec. 8 & 3263 & 14.81 & 9.14 & 12.02 & 9.38 & 7.66 & 10.15 & 11.31 & 10.36 & 15.17 \\
Dec. 9 & 3268 & 14.30 & 9.92 & 11.48 & 7.96 & 5.51 & 9.92 & 14.79 & 8.48 & 17.64 \\
Dec. 10 & 3258 & 22.58 & 7.55 & 14.97 & 5.43 & 2.82 & 6.29 & 16.94 & 6.66 & 16.75 \\
& & & & & & & & & & \\
I-Q range & 1.36 & 0.90 & 4.55 & 3.51 & 8.99 & 0.80 & 4.59 & 2.50 & 5.84 \\
10th - 1st & 13.17 & -5.48 & 11.2 & -8.76 & -28.36 & -0.82 & 12.25 & -1.77 & 8.56 \\
\hline
\end{tabular}

\begin{tabular}{lcccccccccc}
\hline & \multicolumn{8}{c}{ Panel B. Performance transition probabilities (in pct from year $t-2$ to year $t$ ) } \\
\cline { 2 - 10 } $\begin{array}{l}\text { Deciles of } \\
\sigma\left(\varepsilon_{i}\right)\end{array}$ & Obs. & $\mathrm{T}_{1, t-2-}-\mathrm{T}_{1, t}$ & $\mathrm{~T}_{1, t-2-2}-\mathrm{T}_{2, t}$ & $\mathrm{~T}_{1, t-2-2}-\mathrm{T}_{3, t}$ & $\mathrm{~T}_{2, t-2}-\mathrm{T}_{1, t}$ & $\mathrm{~T}_{2, t-2}-\mathrm{T}_{2, t}$ & $\mathrm{~T}_{2, t-2}-\mathrm{T}_{3, t}$ & $\mathrm{~T}_{3, t-2}-\mathrm{T}_{1, t}$ & $\mathrm{~T}_{3, t-2}-\mathrm{T}_{2, t}$ & $\mathrm{~T}_{3, t-2-}-\mathrm{T}_{3, t}$ \\
\cline { 2 - 11 } & & (i) & (ii) & (iii) & (iv) & (v) & (vi) & (vii) & (viii) & (ix) \\
\hline Dec. 1 & 3004 & 9.55 & 12.45 & 4.46 & 13.98 & 30.39 & 9.45 & 4.73 & 9.62 & 5.36 \\
Dec. 2 & 3025 & 11.31 & 12.13 & 3.97 & 15.57 & 20.96 & 10.74 & 6.05 & 11.44 & 7.83 \\
Dec. 3 & 3043 & 12.65 & 10.12 & 7.69 & 12.91 & 17.35 & 10.71 & 8.31 & 10.22 & 10.02 \\
Dec. 4 & 3028 & 10.96 & 9.68 & 7.83 & 11.36 & 14.00 & 12.09 & 10.14 & 11.33 & 12.62 \\
Dec. 5 & 3032 & 10.32 & 8.34 & 8.15 & 10.69 & 12.76 & 11.38 & 10.62 & 12.90 & 14.84 \\
Dec. 6 & 3032 & 10.39 & 8.71 & 11.31 & 9.80 & 10.09 & 11.54 & 11.51 & 11.05 & 15.60 \\
Dec. 7 & 3008 & 12.30 & 8.51 & 12.27 & 10.80 & 7.81 & 11.07 & 11.77 & 10.24 & 15.23 \\
Dec. 8 & 3014 & 14.07 & 9.42 & 12.08 & 8.16 & 7.80 & 9.95 & 12.74 & 10.25 & 15.53 \\
Dec. 9 & 3036 & 13.41 & 8.23 & 13.67 & 7.58 & 4.94 & 8.14 & 16.34 & 10.77 & 16.93 \\
Dec. 10 & 3032 & 19.06 & 7.59 & 15.70 & 6.46 & 2.87 & 6.04 & 19.36 & 6.13 & 16.79 \\
& & & & & & & & & & \\
I-Q range & 2.69 & 1.63 & 4.50 & 3.95 & 8.71 & 1.73 & 3.73 & 1.04 & 4.91 \\
10th - 1st & 9.51 & -4.86 & 11.24 & -7.52 & -27.52 & -3.41 & 14.63 & -3.49 & 11.43 \\
\hline
\end{tabular}




\section{Table IV}

\section{Idiosyncratic Volatility, Fund Investment Objectives, and Transition Probabilities of Performance}

The table documents the characteristics of portfolios of funds grouped by their investment objectives, as classified by Strategic Insight objective codes (ING, GRI, GRO, GMS, SCG, AGG). In Panel A, we first sort funds according to their Carhart (1997) risk-adjusted returns and assign them to performance quintiles. We then compute the frequencies (corrected for the different number of funds in each investment objective) of funds in each investment objective transiting in each performance quintile. In panel A, instead, for each of these investment objectives, we provide descriptive statistics in terms of the extent of average idiosyncratic volatility, dispersion of idiosyncratic volatility, size of the fund (TNA), number of years since inception (Age), management fees (Mgmt fee), and fund portfolio rebalancing (Turnover).

Panel A: Transition Probabilities of Investment Objectives

\begin{tabular}{lcccccc}
\hline & ING & GRI & GRO & GMC & SCG & AGG \\
\hline Fund Alpha [1 - Low] & $10.1 \%$ & $13.9 \%$ & $20.2 \%$ & $21.5 \%$ & $26.5 \%$ & $29.5 \%$ \\
Fund Alpha [2] & $21.2 \%$ & $22.7 \%$ & $21.6 \%$ & $16.3 \%$ & $16.1 \%$ & $15.9 \%$ \\
Fund Alpha [3] & $28.4 \%$ & $25.8 \%$ & $19.9 \%$ & $16.2 \%$ & $14.0 \%$ & $13.6 \%$ \\
Fund Alpha [4] & $25.0 \%$ & $23.8 \%$ & $20.5 \%$ & $18.3 \%$ & $15.1 \%$ & $14.7 \%$ \\
Fund Alpha [5 - High] & $15.3 \%$ & $13.8 \%$ & $17.9 \%$ & $27.8 \%$ & $28.4 \%$ & $26.3 \%$ \\
& & & & & & \\
Q.1 - Q.3 & $-18.3 \%$ & $-11.9 \%$ & $0.3 \%$ & $5.3 \%$ & $12.5 \%$ & $15.9 \%$ \\
Q.5 - Q.3 & $-13.1 \%$ & $-12.0 \%$ & $-2.0 \%$ & $11.6 \%$ & $14.4 \%$ & $12.7 \%$ \\
\hline
\end{tabular}

Panel B: Carhart (1997) Idiosyncratic Volatility Within Investment Objectives

\begin{tabular}{lcccccccc}
\hline & Codes & $\begin{array}{c}\text { No } \\
\text { Funds }\end{array}$ & $\begin{array}{c}\text { Average } \\
\sigma(\varepsilon)\end{array}$ & $\begin{array}{c}\text { Dispersion } \\
\sigma(\varepsilon)\end{array}$ & $\begin{array}{c}\text { TNA } \\
(\$ \mathrm{~m})\end{array}$ & $\begin{array}{c}\text { Age } \\
(\text { years })\end{array}$ & $\begin{array}{c}\text { Mgmt fee } \\
\text { Turnover } \\
\text { (p.a.) }\end{array}$ \\
\hline Income \& Growth & ING & 185 & $1.0 \%$ & $0.4 \%$ & 1230.71 & 6.92 & $0.90 \%$ & 0.66 \\
Growth \& Income & GRI & 545 & $1.1 \%$ & $0.6 \%$ & 1003.38 & 7.86 & $0.99 \%$ & 0.73 \\
Growth & GRO & 941 & $1.4 \%$ & $0.8 \%$ & 808.04 & 7.18 & $1.11 \%$ & 0.87 \\
Mid-Cap & GMC & 172 & $1.9 \%$ & $0.8 \%$ & 693.11 & 5.87 & $1.11 \%$ & 0.92 \\
Small Cap & SCG & 425 & $1.9 \%$ & $0.7 \%$ & 358.86 & 5.39 & $1.22 \%$ & 1.14 \\
Aggr. Growth & AGG & 217 & $2.1 \%$ & $1.4 \%$ & 440.24 & 6.83 & $1.28 \%$ & 1.37 \\
\hline
\end{tabular}


Table V

\section{Characteristics of Fund Portfolios Sorted by their Exposure to Idiosyncratic Volatility}

Over the period 1990 to 2007, we separate portfolios according to their idiosyncratic risk. During the portfolio formation period we first estimate the Carhart (1997) unconditional four-factor model and obtain a vector of regression residuals. We request 36 months of available observations for a fund to be included in the regression. We then rank the residuals into five portfolios (quintiles) and compute the portfolio returns as the equally-weighted average return of all constituent funds over the following month. The weights are readjusted whenever a fund disappears in the portfolio. For each portfolio of idiosyncratic volatility, we then compute its characteristics. For each portfolio we also estimate the factor loadings using the time-series of portfolio returns. In the table we document several portfolio characteristics: Returns are the net absolute portfolio returns. The TNA (\$ million) and Turnover (scaled by the average 12-month TNA of the fund) columns document the average size and turnover of the funds in each quintile portfolio. The pre- (or post-) formation $\sigma(\varepsilon)$ refers to the equally-weighted values of the $\sigma(\varepsilon)$ over the formation (or estimation) period. For each quintile of idiosyncratic risk we also report the average estimated coefficients of the regression. Robust Newey-West (1987) t-statistics are reported in italic.

\begin{tabular}{|c|c|c|c|c|c|c|c|c|c|c|c|c|c|c|}
\hline \multicolumn{15}{|c|}{ Panel A. 36-Month Portfolio Formation Periods } \\
\hline Ranks & \# funds & Mgmt Fee & TNA (\$m) & Turnover & Fund Age & $\begin{array}{c}\text { Pre-form } \\
\sigma(\dot{\varepsilon})\end{array}$ & $\begin{array}{c}\text { Post-form } \\
\sigma(\dot{\varepsilon})\end{array}$ & $\begin{array}{c}\text { Systematic } \\
\text { Risk }\end{array}$ & Size & Value & Momentum & $\begin{array}{c}\text { Pastor - } \\
\text { Stambaugh }\end{array}$ & Adj - $R^{2}$ & $\begin{array}{c}\text { Jarque- } \\
\text { Bera }\end{array}$ \\
\hline 1.Quintile & 438 & $0.91 \%$ & 1280.2 & 0.72 & 9.77 & $0.72 \%$ & $0.26 \%$ & 0.86 & -0.06 & 0.11 & -0.02 & 0.00 & $99.3 \%$ & $<0.01$ \\
\hline$t$-stat & & & & & & & & 55.68 & -3.67 & 5.71 & -1.22 & -0.05 & & \\
\hline 2.Quintile & 438 & $1.03 \%$ & 929.8 & 0.77 & 9.85 & $1.06 \%$ & $0.31 \%$ & 0.91 & 0.02 & 0.09 & -0.01 & -0.02 & $99.2 \%$ & $<0.01$ \\
\hline t-stat & & & & & & & & 61.02 & 1.16 & 4.62 & -0.38 & -0.19 & & \\
\hline 3.Quintile & 437 & $1.14 \%$ & 711.3 & 0.83 & 9.38 & $1.37 \%$ & $0.43 \%$ & 0.95 & 0.17 & 0.05 & 0.03 & -0.05 & $98.9 \%$ & $<0.01$ \\
\hline t-stat & & & & & & & & 47.06 & 8.95 & 2.21 & 1.54 & -0.37 & & \\
\hline 4.Quintile & 438 & $1.21 \%$ & 611.3 & 0.97 & 9.05 & $1.79 \%$ & $0.65 \%$ & 1.00 & 0.32 & -0.01 & 0.06 & -0.01 & $98.2 \%$ & $<0.01$ \\
\hline t-stat & & & & & & & & 33.56 & 11.23 & -0.35 & 2.30 & -0.05 & & \\
\hline 5.Quintile & 437 & $1.38 \%$ & 462.7 & 1.28 & 9.67 & $3.14 \%$ & $1.03 \%$ & 1.00 & 0.42 & -0.05 & 0.05 & -0.22 & $94.1 \%$ & $<0.01$ \\
\hline t-stat & & & & & & & & 21.73 & 7.41 & -0.78 & 1.07 & -0.49 & & \\
\hline 5 th -1 st & & $0.47 \%$ & -817.5 & 0.56 & -0.10 & $2.42 \%$ & $1.04 \%$ & 0.14 & 0.48 & -0.16 & 0.07 & -0.03 & $80.2 \%$ & 0.46 \\
\hline t-stat & & 100.27 & -34.93 & 43.67 & -1.29 & & 7.75 & 2.96 & 8.22 & -2.29 & 1.48 & -0.62 & & \\
\hline All Sample & 2187 & $1.13 \%$ & 799.8 & 0.91 & 9.55 & $1.62 \%$ & $0.44 \%$ & 0.95 & 0.18 & 0.04 & 0.02 & 0.11 & $98.7 \%$ & $<0.01$ \\
\hline t-stat & & & & & & & & 41.29 & 6.88 & 1.25 & 1.13 & 0.45 & & \\
\hline
\end{tabular}




\section{Table VI}

\section{Performance of Portfolios Sorted by Idiosyncratic Volatility}

Over the period 1990 to 2007, we separate portfolios according to their idiosyncratic risk. During the portfolio formation period we first estimate the factor model and obtain a vector of regression residuals. We request 36 months of available observations for a fund to be included in the regression. We then rank the residuals in five portfolios (quintiles) and compute the portfolio returns as the equally-weighted average return of all constituent funds over the following month. Thus, the weights are readjusted whenever a fund disappears in the portfolio. For each portfolio, we then compute the abnormal returns using the time-series of fund portfolio returns. In panel $\mathrm{A}$, for each quintile of idiosyncratic risk we report the average estimated intercept of the regression. We document the risk-adjusted performance obtained using the factor models of Fama and French (1993), Carhart (1997), Pastor and Stambaugh (2003), and Ferson and Schadt (1996). Robust Newey-West (1987) $t$-statistics are reported in italic. In panel B and C, we repeat the analysis of panel A using the Carhart (1997) risk-adjusted returns for funds separated according to whether they are above (Large) or below (Small) the cross-sectional median of the TNA (Panel B) and whether they are above (Old) or below (Young) the cross-sectional median of the Age (Panel C). One, two and three asterisks indicate statistical significance at the $10 \%, 5 \%$, and $1 \%$ level, respectively.

\begin{tabular}{|c|c|c|c|c|c|c|c|}
\hline \multicolumn{8}{|c|}{ Panel A. All Sample } \\
\hline \multirow[t]{2}{*}{ Ranks } & \# funds & Raw Returns & $\begin{array}{c}\text { Standard } \\
\text { Deviation }\end{array}$ & $\begin{array}{l}\text { Fama- } \\
\text { French }\end{array}$ & Carhart & $\begin{array}{c}\text { Ferson - } \\
\text { Schadt }\end{array}$ & $\begin{array}{c}\text { Pastor - } \\
\text { Stambaugh }\end{array}$ \\
\hline & (i) & (ii) & (iii) & (iv) & (v) & (vi) & (vii) \\
\hline \multirow[t]{2}{*}{ Quintile.1 } & 438 & $0.69 \%$ & $2.97 \%$ & $-0.14 \% * * *$ & $-0.12 \% * * *$ & $-0.12 \% * *$ & $-0.12 \% * *$ \\
\hline & & & & -2.79 & -2.43 & -2.36 & -2.32 \\
\hline \multirow[t]{2}{*}{ Quintile.2 } & 438 & $0.71 \%$ & $3.19 \%$ & $-0.14 \% * *$ & $-0.14 \% * *$ & $-0.15 \% * *$ & $-0.13 \% * *$ \\
\hline & & & & -2.29 & -2.35 & -2.38 & -2.20 \\
\hline \multirow[t]{2}{*}{ Quintile.3 } & 437 & $0.80 \%$ & $3.54 \%$ & $-0.14 \% * *$ & $-0.13 \% *$ & $-0.15 \% * *$ & $-0.13 \% *$ \\
\hline & & & & -1.82 & -1.66 & -1.82 & -1.66 \\
\hline \multirow[t]{2}{*}{ Quintile.4 } & 438 & $0.86 \%$ & $4.12 \%$ & $-0.11 \%$ & $-0.13 \%$ & $-0.14 \%$ & $-0.14 \% *$ \\
\hline & & & & -0.94 & -1.21 & -1.25 & -1.33 \\
\hline \multirow[t]{2}{*}{ Quintile.5 } & 437 & $0.74 \%$ & $4.51 \%$ & $-0.23 \%$ & $-0.27 \%$ & $-0.27 \% *$ & $-0.29 \% *$ \\
\hline & & & & -1.24 & -1.26 & -1.47 & -1.49 \\
\hline \multirow[t]{2}{*}{5 th $-1 \mathrm{st}$} & & $0.05 \%$ & $1.94 \%$ & $-0.09 \%$ & $-0.15 \%$ & $-0.15 \%$ & $-0.18 \%$ \\
\hline & & & & -0.45 & -0.78 & -0.83 & -0.97 \\
\hline \multirow[t]{2}{*}{ All funds } & 2187 & $0.74 \%$ & $3.91 \%$ & $-0.15 \% * *$ & $-0.16 \% * *$ & $-0.16 \% * *$ & $-0.16 \% * *$ \\
\hline & & & & -2.03 & -2.07 & -2.08 & -2.13 \\
\hline
\end{tabular}

Panel B. Small vs. Large Funds

\begin{tabular}{|c|c|c|c|c|c|}
\hline \multirow{2}{*}{ Ranks } & \multicolumn{2}{|c|}{ \# funds } & \multicolumn{3}{|c|}{ Carhart } \\
\hline & Small & Large & Small & Large & $L-S$ \\
\hline \multirow[t]{2}{*}{ Quintile.1 } & $7.7 \%$ & $12.7 \%$ & $-0.14 \% * * *$ & $-0.11 \% * *$ & $0.03 \%$ \\
\hline & & & -2.68 & -2.26 & 1.21 \\
\hline \multirow[t]{2}{*}{ Quintile.2 } & $8.4 \%$ & $11.5 \%$ & $-0.14 \% * *$ & $-0.13 \% * * *$ & $0.00 \%$ \\
\hline & & & -2.07 & -2.35 & 0.12 \\
\hline \multirow[t]{2}{*}{ Quintile.3 } & $9.3 \%$ & $11.0 \%$ & $-0.11 \%$ & $-0.14 \% * *$ & $-0.03 \%$ \\
\hline & & & -1.10 & -1.76 & -0.60 \\
\hline \multirow[t]{2}{*}{ Quintile.4 } & $9.2 \%$ & $10.7 \%$ & $-0.12 \%$ & $-0.14 \%$ & $-0.01 \%$ \\
\hline & & & -1.13 & -1.29 & -0.32 \\
\hline \multirow[t]{2}{*}{ Quintile.5 } & $9.1 \%$ & $10.5 \%$ & $-0.20 \%$ & $-0.27 \% *$ & $-0.06 \%$ \\
\hline & & & -1.08 & -1.40 & -0.81 \\
\hline \multirow[t]{2}{*}{5 th $-1 \mathrm{st}$} & & & $-0.06 \%$ & $-0.16 \%$ & \\
\hline & & & -0.36 & -0.90 & \\
\hline
\end{tabular}




\section{Table VI - Continued}

\begin{tabular}{|c|c|c|c|c|c|}
\hline \multirow{3}{*}{ Ranks } & \multicolumn{4}{|c|}{ Panel C. Young vs. Old Funds } & \\
\hline & \multicolumn{2}{|c|}{ \# funds } & \multicolumn{3}{|c|}{ Carhart } \\
\hline & Young & Old & Young & Old & $\mathrm{O}-\mathrm{Y}$ \\
\hline \multirow[t]{2}{*}{ Quintile.1 } & $5.2 \%$ & $14.8 \%$ & $-0.13 \% * *$ & $-0.12 \% * * *$ & $0.00 \%$ \\
\hline & & & -2.03 & -2.50 & 0.04 \\
\hline \multirow[t]{2}{*}{ Quintile.2 } & $5.3 \%$ & $14.7 \%$ & $-0.14 \% *$ & $-0.14 \% * * *$ & $-0.01 \%$ \\
\hline & & & -1.59 & -2.47 & -0.14 \\
\hline \multirow[t]{2}{*}{ Quintile.3 } & $5.5 \%$ & $14.5 \%$ & $-0.14 \%$ & $-0.14 \% * *$ & $0.00 \%$ \\
\hline & & & -1.12 & -1.68 & 0.05 \\
\hline \multirow[t]{2}{*}{ Quintile.4 } & $5.4 \%$ & $14.5 \%$ & $-0.19 \% *$ & $-0.11 \%$ & $0.08 \%$ \\
\hline & & & -1.40 & -1.06 & 1.07 \\
\hline \multirow[t]{2}{*}{ Quintile.5 } & $4.5 \%$ & $15.5 \%$ & $-0.18 \%$ & $-0.28 \%$ & $-0.10 \%$ \\
\hline & & & -0.84 & -1.11 & -0.68 \\
\hline \multirow[t]{2}{*}{5 th $-1 \mathrm{st}$} & & & $-0.03 \%$ & $-0.16 \%$ & \\
\hline & & & -0.15 & -0.99 & \\
\hline
\end{tabular}


Table VII

The Effect of Idiosyncratic Volatility on Mutual Fund Net Money Flows

This table reports the results of the regression of investors' net money flows on fund performance with and without controlling for the extent of idiosyncratic risk-taking in the period from January 1994 to December 2007. The dependent variable is the yearly percentage growth rate in fund net money flows $\left(N M F_{i, t}\right)$. The lagged control variables include: logarithm of TNA $(\log T N A)$ to proxy for the size of the fund; Fund Age, calculated as the logarithm of the number of months since fund inception; portfolio Turnover consisting of the aggregate sales or aggregate purchases of securities; Volatility of monthly returns; N.Funds Family, computed as the number of funds in the family; Mgmt fee is funds management fee; Distribut.fee is computed as fund $12 \mathrm{~b}-1$ fees plus $1 / 7^{\text {th }}$ of front-end loads. As a proxy for fund idiosyncratic volatility $(\sigma(\varepsilon))$ and performance (Perf) we use, respectively, the volatility of residuals and the intercept from a 36-month Carhart (1997) factor model. In order to capture the non-linearity in the flow-performance relationship, in column (iv) we use two dummy variables $I_{M}$ and $I_{H}$ which equal 1 if the fund is in the middle or top tercile of performance, respectively. In column (iii), instead, fund performance is computed using the Sirri and Tufano (1998) fractional rankings. We also control for the sensitivity of the dependent variable to different levels of idiosyncratic risk-taking by using dummies of quintiles of idiosyncratic volatility $(Q . n[\sigma(\varepsilon)])$, where dummy Q.1 $[\sigma(\varepsilon)]$ equals 1 for funds in the bottom quintile of idiosyncratic volatility (low), while dummy Q.5 $[\sigma(\varepsilon)]$ equals 1 for funds in the top quintile of idiosyncratic volatility (high). Column (v) to (viii) document the results of different estimation models: Fma-Macbeth $(F-M)$, Fixed-Effect $(F-E)$ with panel-corrected standard errors (Petersen, 2009), and BetweenEffect $(B-E)$. One, two and three asterisks indicate statistical significance at the $10 \%, 5 \%$, and $1 \%$ level, respectively.

\begin{tabular}{|c|c|c|c|c|c|c|c|}
\hline & \multicolumn{7}{|c|}{ Net Money Flows $\left(N M F_{i, t}\right)$} \\
\hline & (i) & (ii) & (iii) & (iv) & $(v)^{\mathrm{F}-\mathrm{M}}$ & (vi) ${ }^{\text {F-E }}$ & (vii) ${ }^{\mathrm{B}-\mathrm{E}}$ \\
\hline $\log$ TNA & $\begin{array}{c}-0.023 * * * \\
(0.004)\end{array}$ & $\begin{array}{c}-0.023 * * * \\
(0.004)\end{array}$ & $\begin{array}{c}-0.036^{* * *} \\
(0.005)\end{array}$ & $\begin{array}{c}-0.025^{* * *} \\
(0.004)\end{array}$ & $\begin{array}{c}-0.025^{* * *} \\
(0.005)\end{array}$ & $\begin{array}{c}-0.023 * * * \\
(0.004)\end{array}$ & $\begin{array}{c}-0.021 * * * \\
(0.002)\end{array}$ \\
\hline Fund age & $\begin{array}{c}-0.048^{* * *} \\
(0.005)\end{array}$ & $\begin{array}{c}-0.048 * * * \\
(0.004)\end{array}$ & $\begin{array}{c}-0.083^{* * *} \\
(0.008)\end{array}$ & $\begin{array}{c}-0.047 * * * \\
(0.005)\end{array}$ & $\begin{array}{c}-0.047 * * * \\
(0.005)\end{array}$ & $\begin{array}{c}-0.058^{* * * *} \\
(0.006)\end{array}$ & $\begin{array}{c}0.013 \\
(0.010)\end{array}$ \\
\hline N.Funds Family & $\begin{array}{l}0.001 * * \\
(0.000)\end{array}$ & $\begin{array}{c}0.001 * * \\
(0.000)\end{array}$ & $\begin{array}{c}0.001 * * * \\
(0.000)\end{array}$ & $\begin{array}{c}0.001^{* * *} \\
(0.000)\end{array}$ & $\begin{array}{c}0.001 * * \\
(0.000)\end{array}$ & $\begin{array}{c}0.000 \\
(0.000)\end{array}$ & $\begin{array}{l}-0.000 \\
(0.000)\end{array}$ \\
\hline Turnover & $\begin{array}{l}0.016^{*} \\
(0.008)\end{array}$ & $\begin{array}{c}0.014 \\
(0.008)\end{array}$ & $\begin{array}{c}0.004 \\
(0.004)\end{array}$ & $\begin{array}{c}0.017 * \\
(0.009)\end{array}$ & $\begin{array}{c}0.021 * * \\
(0.008)\end{array}$ & $\begin{array}{c}0.015 \\
(0.010)\end{array}$ & $\begin{array}{c}0.019 * * * \\
(0.005)\end{array}$ \\
\hline Volatility & $\begin{array}{c}0.287 \\
(0.708)\end{array}$ & $\begin{array}{c}0.774 \\
(1.114)\end{array}$ & $\begin{array}{c}0.029 \\
(0.496)\end{array}$ & $\begin{array}{l}-0.252 \\
(0.625)\end{array}$ & $\begin{array}{c}0.118 \\
(0.683)\end{array}$ & $\begin{array}{l}-0.888 \\
(0.787)\end{array}$ & $\begin{array}{l}-0.379 \\
(0.339)\end{array}$ \\
\hline Perf & $\begin{array}{c}1.630 * * * \\
(0.134)\end{array}$ & $\begin{array}{c}1.736 * * * \\
(0.137)\end{array}$ & $\begin{array}{c}0.504 * * * \\
(0.129)\end{array}$ & $\begin{array}{c}0.444 * * \\
(0.160)\end{array}$ & $\begin{array}{c}2.827 * * * \\
(0.266)\end{array}$ & $\begin{array}{c}2.803 * * * \\
(0.247)\end{array}$ & $\begin{array}{c}3.490 * * * \\
(0.461)\end{array}$ \\
\hline Perf * IM & & & $\begin{array}{c}0.347 * * * \\
(0.069)\end{array}$ & $\begin{array}{c}0.114 \\
(0.707)\end{array}$ & & & \\
\hline Perf * IH & & & $\begin{array}{c}1.560^{* * *} \\
(0.146)\end{array}$ & $\begin{array}{c}1.396^{* * *} \\
(0.444)\end{array}$ & & & \\
\hline IM & & & & $\begin{array}{c}0.032 * * * \\
(0.008)\end{array}$ & & & \\
\hline $\mathrm{IH}$ & & & & $\begin{array}{c}0.100 * * * \\
(0.012)\end{array}$ & & & \\
\hline$\sigma(\varepsilon)$ & & $\begin{array}{c}0.252 \\
(1.255)\end{array}$ & & & & & \\
\hline Perf ${ }^{*} \mathrm{Q} .2[\sigma(\varepsilon)]$ & & & & & $\begin{array}{l}-0.177 \\
(0.354)\end{array}$ & $\begin{array}{l}-0.257 \\
(0.270)\end{array}$ & $\begin{array}{l}-0.764 \\
(0.583)\end{array}$ \\
\hline Perf *Q.3[ $\sigma(\varepsilon)]$ & & & & & $\begin{array}{l}-0.380 \\
(0.301)\end{array}$ & $\begin{array}{l}-0.565^{*} \\
(0.323)\end{array}$ & $\begin{array}{l}-0.989 * \\
(0.540)\end{array}$ \\
\hline Perf *Q.4[ $\sigma(\varepsilon)]$ & & & & & $\begin{array}{c}-0.837 * * \\
(0.282)\end{array}$ & $\begin{array}{c}-1.126^{* * *} \\
(0.295)\end{array}$ & $\begin{array}{c}-1.156^{* *} \\
(0.520)\end{array}$ \\
\hline Perf *Q.5[ $\sigma(\varepsilon)]$ & & & & & $\begin{array}{c}-1.559 * * * \\
(0.417)\end{array}$ & $\begin{array}{c}-1.903 * * * \\
(0.270)\end{array}$ & $\begin{array}{c}-2.069 * * * \\
(0.482)\end{array}$ \\
\hline Mgmt fee & $\begin{array}{c}-3.957 * * * \\
(1.090)\end{array}$ & $\begin{array}{c}-4.546^{* * *} \\
(1.005)\end{array}$ & $\begin{array}{c}-8.274 * * * \\
(1.069)\end{array}$ & $\begin{array}{c}-5.204^{* * *} \\
(1.160)\end{array}$ & $\begin{array}{c}-3.782 * * \\
(1.519)\end{array}$ & $\begin{array}{c}-4.894 * * * \\
(1.309)\end{array}$ & $\begin{array}{c}-4.887 * * * \\
(1.281)\end{array}$ \\
\hline Distribut. fee & $\begin{array}{c}-6.030 * * * \\
(1.559)\end{array}$ & $\begin{array}{c}-6.021 * * * \\
(1.555)\end{array}$ & $\begin{array}{c}-8.140^{* * *} \\
(1.744)\end{array}$ & $\begin{array}{c}-5.945^{* * *} \\
(1.524)\end{array}$ & $\begin{array}{c}-6.437 * * * \\
(1.573)\end{array}$ & $\begin{array}{c}-5.609 * * * \\
(2.083)\end{array}$ & $\begin{array}{c}-8.463 * * * \\
(1.668)\end{array}$ \\
\hline adj. R-sq & $5.9 \%$ & $5.7 \%$ & $15.7 \%$ & $5.9 \%$ & $9.1 \%$ & $13.9 \%$ & $16.4 \%$ \\
\hline $\mathrm{N}$ & 21742 & 21742 & 30222 & 21742 & 21242 & 21242 & 21242 \\
\hline
\end{tabular}


Table VIII

Fund Idiosyncratic Risk and Change in the Flow-Performance Sensitivity

This table reports the results of the regression of the flow-performance sensitivities to idiosyncratic volatility during the period from January 1994 to December 2007. The dependent variable is the flow-performance sensitivity $\left(\Phi_{i, t}\right)$, computed as the first derivative of the yearly percentage growth rate in fund net money flows $\left(N M F_{i, t}\right)$ with respect to performance and several control variables $(\log T N A$, Fund age, N.Fund Family, Turnover, Flows, Volatility, Management fees, Distrbution fees), and dummy variables for small funds, years, and investment objectives. The independent variable is represented by the level of fund idiosyncratic risk-taking $(\sigma(\varepsilon))$. The table documents the results of different estimation models: Fama-Macbeth $(F-M)$, fund and year Fixed-Effect $(F-E)$ with panel-corrected standard errors (Petersen, 2009), and Between-Effect $(B-E)$. In column (ii) we control for the possibility that the relationship between flow-performance sensitivity is not linear in the level of idiosyncratic risk by introducing the squared value of the independent variable. In column (iii), (v) and (vii), instead, we re-estimate the dependent variable $\left(\Phi_{i, t}\right)$ after adding an interaction term between performance and investors' participation costs $(P C)$. Our proxy for participation costs is a dummy variable Star that equals 1 if the fund is part of a family comprising one or more funds which ranked in the top $5 \%$ of the risk-adjusted performance distribution in that year. In last two columns we estimate the model with FamaMacbeth robust standard errors in the two sub-periods from 1994 to 2000 (in column (viii)) and from 2001 to 2007 (in column (ix)). One, two and three asterisks indicate statistical significance at the $10 \%, 5 \%$, and $1 \%$ level, respectively.

\begin{tabular}{|c|c|c|c|c|c|c|c|c|c|}
\hline & \multicolumn{9}{|c|}{ Flow-Performance Sensitivity $\left(\Phi_{i, t}\right)$} \\
\hline & F-M & F-M & $\begin{array}{c}\text { F-M } \\
\text { with } P C\end{array}$ & F-E & $\begin{array}{c}\text { F-E } \\
\text { with } P C\end{array}$ & B-E & $\begin{array}{c}\text { B-E } \\
\text { with } P C\end{array}$ & F-M ${ }^{\{94-00\}}$ & F-M $M^{\{01-07\}}$ \\
\hline & (i) & (ii) & (iii) & (iv) & (v) & (vi) & (vii) & (viii) & (ix) \\
\hline$\sigma(\varepsilon)$ & $\begin{array}{c}-1.539 * * * \\
(0.364)\end{array}$ & $\begin{array}{c}-2.483^{* *} \\
(0.996)\end{array}$ & $\begin{array}{c}-4.032^{* * * *} \\
(1.332)\end{array}$ & $\begin{array}{c}-1.444 * * * \\
(0.306)\end{array}$ & $\begin{array}{c}-3.822^{* *} \\
(1.519)\end{array}$ & $\begin{array}{c}-1.227^{* * *} \\
(0.207)\end{array}$ & $\begin{array}{c}-4.049 * * * \\
(0.520)\end{array}$ & $\begin{array}{c}-1.020^{* *} \\
(0.419)\end{array}$ & $\begin{array}{c}-2.006^{* * *} \\
(0.368)\end{array}$ \\
\hline$\sigma(\varepsilon) \_$squared & & $\begin{array}{c}0.140 \\
(0.105)\end{array}$ & & & & & & & \\
\hline adj. R-sq & $13.1 \%$ & $13.0 \%$ & $3.5 \%$ & $14.9 \%$ & $3.7 \%$ & $33.8 \%$ & $18.0 \%$ & $14.4 \%$ & $15.6 \%$ \\
\hline $\mathrm{N}$ & 25301 & 25301 & 20950 & 25301 & 20950 & 25301 & 20950 & 10393 & 14908 \\
\hline
\end{tabular}




\section{Table IX \\ Management Fees Across Portfolios of Idiosyncratic Volatility and Fund Characteristics}

In this table, we document the average management fee across portfolios of idiosyncratic volatility and fund characteristics over the period from 1994 to 2007. Mutual funds are first sorted according to their lagged value of idiosyncratic risk and assigned to equal-sized portfolio quintiles. The portfolio with low (high) idiosyncratic risk is denoted as Low IR (High IR). In a second step, funds are also sorted in ascending order and assigned to equal-sized portfolio quintiles on the basis of each of the following lagged fund characteristics: logarithm of fund total net assets (TNA) in panel A, logarithm of TNA of the family of funds (fTNA) in panel B, portfolio turnover in panel C, and logarithm of fund age since inception in panel D. The significance levels are abbreviated with asterisks: One, two, and three asterisks indicate significance at the $10 \%, 5 \%$, and $1 \%$ level, respectively.

\begin{tabular}{|c|c|c|c|c|c|c|}
\hline \multirow{2}{*}{$\begin{array}{l}\text { Idiosyncratic } \\
\text { Risk }_{t-1}\end{array}$} & \multicolumn{6}{|c|}{ Panel A: TNA $A_{t-1}$} \\
\hline & TNA. Low & TNA. 2 & TNA. 3 & TNA. 4 & TNA. High & $\mathrm{H}-\mathrm{L}$ \\
\hline Low IR & 1.042 & 1.035 & 0.966 & 0.908 & 0.748 & $-0.294 * * *$ \\
\hline IR. 2 & 1.209 & 1.155 & 1.068 & 1.013 & 0.838 & $-0.371 * * *$ \\
\hline IR. 3 & 1.321 & 1.254 & 1.148 & 1.091 & 0.944 & $-0.377 * * *$ \\
\hline IR. 4 & 1.416 & 1.305 & 1.239 & 1.167 & 1.001 & $-0.415^{* * *}$ \\
\hline High IR & 1.691 & 1.516 & 1.386 & 1.251 & 1.078 & $-0.613 * * *$ \\
\hline High - Low & $0.649 * * *$ & $0.482 * * *$ & $0.420 * * *$ & $0.343^{* * *}$ & $0.330 * * *$ & \\
\hline \multirow{2}{*}{$\begin{array}{l}\text { Idiosyncratic } \\
\text { Risk }_{t-1}\end{array}$} & \multicolumn{6}{|c|}{ Panel B: Family $T N A_{t-1}$} \\
\hline & fTNA.Low & fTNA. 2 & fTNA. 3 & fTNA. 4 & fTNA. High & $\mathrm{H}-\mathrm{L}$ \\
\hline Low IR & 1.056 & 1.017 & 0.947 & 0.867 & 0.751 & $-0.305 * * *$ \\
\hline IR. 2 & 1.213 & 1.122 & 1.053 & 0.976 & 0.852 & $-0.361 * * *$ \\
\hline IR. 3 & 1.302 & 1.219 & 1.136 & 1.062 & 0.979 & $-0.323 * * *$ \\
\hline IR. 4 & 1.393 & 1.278 & 1.224 & 1.133 & 1.040 & $-0.353 * * *$ \\
\hline High IR & 1.634 & 1.469 & 1.354 & 1.217 & 1.150 & $-0.484 * * *$ \\
\hline High - Low & $0.578 * * *$ & $0.452 * * *$ & $0.407 * * *$ & $0.350 * * *$ & $0.399 * * *$ & \\
\hline \multirow{2}{*}{$\begin{array}{l}\text { Idiosyncratic } \\
\text { Risk }_{t-1}\end{array}$} & \multicolumn{6}{|c|}{ Panel C: Turnover ${ }_{t-1}$} \\
\hline & Turnr. Low & Turnr. 2 & Turnr. 3 & Turnr. 4 & Turnr. High & $\mathrm{H}-\mathrm{L}$ \\
\hline Low IR & 0.816 & 0.919 & 0.931 & 0.953 & 1.032 & $0.216^{* * *}$ \\
\hline IR. 2 & 0.978 & 1.031 & 1.068 & 1.043 & 1.062 & $0.084 * * *$ \\
\hline IR. 3 & 1.106 & 1.127 & 1.123 & 1.167 & 1.196 & $0.091 * * *$ \\
\hline IR. 4 & 1.145 & 1.176 & 1.203 & 1.271 & 1.234 & $0.089 * * *$ \\
\hline High IR & 1.260 & 1.322 & 1.374 & 1.395 & 1.444 & $0.184 * * *$ \\
\hline High - Low & $0.443 * * *$ & $0.374 * * *$ & $0.41 * * *$ & $0.410 * * *$ & $0.378 * * *$ & \\
\hline \multirow{2}{*}{$\begin{array}{l}\text { Idiosyncratic } \\
\text { Risk }_{t-1}\end{array}$} & \multicolumn{6}{|c|}{ Panel D: Fund Age ${ }_{t-1}$} \\
\hline & Age. Low & Age. 2 & Age. 3 & Age. 4 & Age. High & $\mathrm{H}-\mathrm{L}$ \\
\hline Low IR & 0.780 & 0.928 & 0.935 & 0.947 & 0.827 & 0.047 \\
\hline IR. 2 & 1.006 & 1.079 & 1.080 & 1.037 & 0.924 & -0.082 \\
\hline IR. 3 & 1.177 & 1.190 & 1.152 & 1.122 & 1.058 & -0.119 \\
\hline IR. 4 & 1.285 & 1.268 & 1.238 & 1.176 & 1.139 & -0.146 \\
\hline High IR & 1.358 & 1.396 & 1.378 & 1.382 & 1.279 & -0.079 \\
\hline High - Low & $0.578^{*}$ & $0.467 * * *$ & $0.443 * * *$ & $0.435 * * *$ & $0.452 * * *$ & \\
\hline
\end{tabular}




\section{Table X \\ Sensitivities of Management Fees to Idiosyncratic Volatility}

This table examines the sensitivities of mutual fund management fees to fund idiosyncratic volatility. We run a multivariate Fama-MacBeth (1973) regression in the period from January 1994 to December 2007. The dependent variable (expressed in percentage terms) is the fund management fees (operating expenses minus 12B-1 fees). The lagged control variables include: logarithm of TNA $(\log T N A)$ to proxy for the size of the fund; Fund Age, calculated as the logarithm of the number of months since fund inception; portfolio Turnover consisting of the aggregate sales or aggregate purchases of securities; Volatility of monthly returns; N.Funds Family, computed as the number of funds in the family; Flows is the yearly percentage growth rate in fund net money flows. As a proxy for fund idiosyncratic volatility and performance we use, respectively, the intercept and volatility of residuals from a 36-month Carhart (1997) factor model. To account for non-linearity in the fee-performance relationship we include the squared value of fund performance. We also control for the sensitivity of the dependent variable to different levels of idiosyncratic risk-taking by using dummies of quintiles of idiosyncratic volatility $(Q \cdot n[\sigma(\varepsilon)])$, where dummy Q.1 $[\sigma(\varepsilon)]$ equals 1 for funds in the bottom quintile of idiosyncratic volatility (low), while dummy Q.5 $[\sigma(\varepsilon)]$ equals 1 for funds in the top quintile of idiosyncratic volatility (high). We use the variable Small that equals 1 if the size of the fund is in the bottom 5\% in the fund size distribution in that year, and Star that equals 1 if the fund is part of a family comprising one or more funds which ranked in the top $5 \%$ of the risk-adjusted performance distribution in that year. All regressions include untabulated dummy variables for share classes and investment objectives. Fama-Macbeth standard errors are in parentheses. In column (viii), we cluster standard errors by fund and time and use year-fixed effect. One, two and three asterisks indicate statistical significance at the $10 \%, 5 \%$, and $1 \%$ level, respectively.

\begin{tabular}{|c|c|c|c|c|c|c|c|c|}
\hline & \multicolumn{8}{|c|}{ Yearly Management Fee (x 100) } \\
\hline & (i) & (ii) & (iii) & (iv) & (v) & (vi) & (vii) & $(\text { viii })^{\mathrm{a}}$ \\
\hline \multirow[t]{2}{*}{$\log$ TNA } & $-0.067 * * *$ & $-0.062 * * *$ & $-0.069 * * *$ & $-0.065^{* * *}$ & $-0.069 * * *$ & $-0.065^{* * *}$ & $-0.066^{* * *}$ & $-0.061 * * *$ \\
\hline & $(0.009)$ & $(0.008)$ & $(0.009)$ & $(0.008)$ & $(0.009)$ & $(0.008)$ & $(0.007)$ & $(0.005)$ \\
\hline \multirow[t]{2}{*}{ Fund age } & -0.001 & -0.000 & 0.001 & -0.005 & 0.001 & -0.005 & -0.003 & -0.004 \\
\hline & $(0.005)$ & $(0.008)$ & $(0.008)$ & $(0.008)$ & $(0.008)$ & $(0.008)$ & $(0.006)$ & $(0.012)$ \\
\hline \multirow[t]{2}{*}{ N.Funds Family } & $-0.002 * * *$ & $-0.002 * * *$ & $-0.002 * * *$ & $-0.002 * * *$ & $-0.002 * * *$ & $-0.002 * * *$ & $-0.002 * * *$ & $-0.001 * * *$ \\
\hline & $(0.000)$ & $(0.000)$ & $(0.000)$ & $(0.000)$ & $(0.000)$ & $(0.000)$ & $(0.000)$ & $(0.000)$ \\
\hline \multirow[t]{2}{*}{ Turnover } & $0.043 * * *$ & $0.034 * * *$ & $0.045 * * *$ & $0.030 * * *$ & $0.038^{* * *}$ & $0.028 * * *$ & $0.025^{* * *}$ & $0.024 * * *$ \\
\hline & $(0.006)$ & $(0.006)$ & $(0.005)$ & $(0.004)$ & $(0.005)$ & $(0.005)$ & $(0.006)$ & $(0.006)$ \\
\hline \multirow[t]{2}{*}{ Flows } & $-0.042 * * *$ & $-0.052 * * *$ & $-0.037 * * *$ & $-0.037 * * *$ & $-0.043^{* * *}$ & $-0.040 * * *$ & $-0.030^{* * *}$ & $-0.050 * * *$ \\
\hline & $(0.009)$ & $(0.004)$ & $(0.010)$ & $(0.010)$ & $(0.009)$ & $(0.008)$ & $(0.009)$ & $(0.008)$ \\
\hline \multirow[t]{2}{*}{ Volatility } & -0.217 & $-1.194 * *$ & $3.385^{* * *}$ & $-1.136^{* *}$ & $2.949 * * *$ & $-1.240 * *$ & -0.839 & $-1.081^{* *}$ \\
\hline & $(0.476)$ & $(0.539)$ & $(1.021)$ & $(0.523)$ & $(0.960)$ & $(0.481)$ & $(0.985)$ & $(0.471)$ \\
\hline \multirow[t]{2}{*}{$\sigma(\varepsilon)$} & $10.688^{* * *}$ & $14.673^{* * *}$ & & $14.618^{* * *}$ & & $14.763^{* * *}$ & $10.228^{* * *}$ & $7.723 * * *$ \\
\hline & $(0.885)$ & $(2.397)$ & & $(2.357)$ & & $(1.972)$ & $(2.762)$ & (1.909) \\
\hline \multirow[t]{2}{*}{ alpha } & & & -0.213 & -0.241 & 0.063 & -0.172 & -0.225 & $-0.300^{* *}$ \\
\hline & & & $(0.162)$ & $(0.163)$ & $(0.168)$ & $(0.156)$ & $(0.132)$ & $(0.135)$ \\
\hline \multicolumn{9}{|l|}{$\alpha$ lpha $*$ Mid } \\
\hline \multicolumn{9}{|l|}{ alpha * High } \\
\hline \multirow[t]{2}{*}{ alpha_squared } & & & & & $8.651^{* * *}$ & 2.716 & & \\
\hline & & & & & $(2.554)$ & $(2.288)$ & & \\
\hline \multirow[t]{2}{*}{ 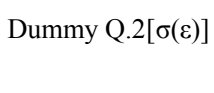 } & & & & & & & $0.041^{* * *}$ & $0.068^{* * *}$ \\
\hline & & & & & & & $(0.007)$ & $(0.014)$ \\
\hline
\end{tabular}


Table X - Continued

\begin{tabular}{|c|c|c|c|c|c|c|c|c|}
\hline & \multicolumn{8}{|c|}{ Yearly Management Fee (x 100) } \\
\hline & (i) & (ii) & (iii) & (iv) & (v) & (vi) & (vii) & $\left(\right.$ viii $^{\mathrm{a}}$ \\
\hline Dummy Q.3 $[\sigma(\varepsilon)]$ & & & & & & & $\begin{array}{c}0.087 * * * \\
(0.009)\end{array}$ & $\begin{array}{c}0.113^{* * *} \\
(0.014)\end{array}$ \\
\hline Dummy Q.4[ $\sigma(\varepsilon)]$ & & & & & & & $\begin{array}{c}0.106 * * * \\
(0.021)\end{array}$ & $\begin{array}{r}0.138^{* * *} \\
(0.022)\end{array}$ \\
\hline Dummy Q.5[ $\sigma(\varepsilon)]$ & & & & & & & $\begin{array}{c}0.137 * * * \\
(0.028)\end{array}$ & $\begin{array}{r}0.190 * * * \\
(0.028)\end{array}$ \\
\hline D.Star & & $\begin{array}{l}0.109^{*} \\
(0.056)\end{array}$ & $\begin{array}{c}0.095 * * \\
(0.032)\end{array}$ & $\begin{array}{c}0.058 \\
(0.033)\end{array}$ & $\begin{array}{c}0.088 * * \\
(0.031)\end{array}$ & $\begin{array}{l}0.057^{*} \\
(0.032)\end{array}$ & $\begin{array}{c}0.037 \\
(0.034)\end{array}$ & $\begin{array}{c}0.043 \\
(0.030)\end{array}$ \\
\hline D.Small & & $\begin{array}{l}-0.068 \\
(0.055)\end{array}$ & $\begin{array}{c}0.031 \\
(0.115)\end{array}$ & $\begin{array}{l}-0.001 \\
(0.105)\end{array}$ & $\begin{array}{c}0.020 \\
(0.110)\end{array}$ & $\begin{array}{c}0.008 \\
(0.101)\end{array}$ & $\begin{array}{c}0.018 \\
(0.112)\end{array}$ & $\begin{array}{l}-0.088 \\
(0.067)\end{array}$ \\
\hline adj. R-sq & $29.4 \%$ & $26.3 \%$ & $21.9 \%$ & $28.1 \%$ & $22.9 \%$ & $28.3 \%$ & $30.1 \%$ & $32.9 \%$ \\
\hline $\mathrm{N}$ & 27865 & 23517 & 20372 & 20372 & 20372 & 20372 & 19640 & 19640 \\
\hline
\end{tabular}

a: Year-fixed effect with standard errors clustered by fund and time 


\section{Table XI \\ Sensitivities of Management Fees to Performance Controlling for Idiosyncratic Volatility}

This table examines the sensitivities of mutual fund management fees to past performance while controlling for the level of idiosyncratic volatility of the fund. We run a multivariate Fama-MacBeth (1973) regression in the period from January 1994 to December 2007. The dependent variable (expressed in percentage terms) is the fund management fees (operating expenses minus 12B-1 fees). The lagged control variables include: logarithm of TNA $(\log T N A)$ to proxy for the size of the fund; Fund Age, calculated as the logarithm of the number of months since fund inception; portfolio Turnover consisting of the aggregate sales or aggregate purchases of securities; Volatility of monthly returns; N.Funds Family, computed as the number of funds in the family; Flows is the yearly percentage growth rate in fund net money flows. As a proxy for fund idiosyncratic volatility and performance we use, respectively, the intercept and volatility of residuals from a 36-month Carhart (1997) factor model. We also rank and separate fund performance into three terciles using lagged dummy variables (Mid and High). We control for the effect of fund idiosyncratic risk on fee-performance relationship $(\sigma(\varepsilon))$ by interacting performance measures with the variable $\sigma(\varepsilon) \times 100$ for each tercile of performance. Columns from (i) to (iii) report the coefficients of different models related to the entire sample. In columns (iv) and (v), instead, we restrict our analysis specifically to funds that left unchanged their management fee. All regressions include untabulated dummy variables for share classes, investment objectives, small funds (Small), and star funds (Star). Fama-Macbeth standard errors are reported in parentheses. One, two and three asterisks indicate statistical significance at the $10 \%, 5 \%$, and $1 \%$ level, respectively.

\begin{tabular}{|c|c|c|c|c|c|}
\hline & \multicolumn{5}{|c|}{ Yearly Management Fee (x 100) } \\
\hline & (i) & (ii) & (iii) & (iv) & (v) \\
\hline $\log$ TNA & $\begin{array}{c}-0.069 * * * \\
(0.009)\end{array}$ & $\begin{array}{c}-0.065^{* * *} \\
(0.008)\end{array}$ & $\begin{array}{c}-0.074 * * * \\
(0.007)\end{array}$ & $\begin{array}{c}-0.074 * * * \\
(0.007)\end{array}$ & $\begin{array}{c}-0.071 * * * \\
(0.007)\end{array}$ \\
\hline Fund age & $\begin{array}{c}0.000 \\
(0.008)\end{array}$ & $\begin{array}{l}-0.005 \\
(0.008)\end{array}$ & $\begin{array}{l}-0.003 \\
(0.005)\end{array}$ & $\begin{array}{c}0.055 \\
(0.036)\end{array}$ & $\begin{array}{c}0.047 \\
(0.036)\end{array}$ \\
\hline N.Funds Family & $\begin{array}{c}-0.002 * * * \\
(0.000)\end{array}$ & $\begin{array}{c}-0.002 * * * \\
(0.000)\end{array}$ & $\begin{array}{c}-0.001 * * * \\
(0.000)\end{array}$ & $\begin{array}{l}-0.003 * \\
(0.002)\end{array}$ & $\begin{array}{c}-0.003 * * \\
(0.001)\end{array}$ \\
\hline Turnover & $\begin{array}{c}0.038 * * * \\
(0.004)\end{array}$ & $\begin{array}{c}0.029 * * * \\
(0.004)\end{array}$ & $\begin{array}{c}0.033 * * * \\
(0.005)\end{array}$ & $\begin{array}{c}0.042 * * * \\
(0.011)\end{array}$ & $\begin{array}{c}0.033 * * * \\
(0.010)\end{array}$ \\
\hline Flows & $\begin{array}{c}-0.046^{* * *} \\
(0.009)\end{array}$ & $\begin{array}{c}-0.041 * * * \\
(0.009)\end{array}$ & $\begin{array}{l}-0.023 \\
(0.014)\end{array}$ & $\begin{array}{l}-0.038^{*} \\
(0.020)\end{array}$ & $\begin{array}{l}-0.036 \\
(0.021)\end{array}$ \\
\hline Volatility & $\begin{array}{c}2.913 * * \\
(0.988)\end{array}$ & $\begin{array}{c}-1.110 * * \\
(0.491)\end{array}$ & $\begin{array}{c}0.048 \\
(0.400)\end{array}$ & $\begin{array}{c}2.905 * * * \\
(0.698)\end{array}$ & $\begin{array}{l}-0.477 \\
(0.697)\end{array}$ \\
\hline$\sigma(\varepsilon)$ & & $\begin{array}{c}13.930^{* * *} \\
(2.255)\end{array}$ & $\begin{array}{c}9.458 * * * \\
(1.154)\end{array}$ & & $\begin{array}{c}11.930 * * * \\
(2.337)\end{array}$ \\
\hline alpha & $\begin{array}{c}-1.121 * * * \\
(0.287)\end{array}$ & $\begin{array}{c}-0.614^{* *} \\
(0.250)\end{array}$ & $\begin{array}{l}-0.261 \\
(0.379)\end{array}$ & $\begin{array}{c}-0.847 * * \\
(0.356)\end{array}$ & $\begin{array}{l}-0.323 \\
(0.321)\end{array}$ \\
\hline alpha $*[\sigma(\varepsilon) * 100]$ & & & $\begin{array}{c}-0.446^{* *} \\
(0.200)\end{array}$ & & \\
\hline$\alpha$ lpha $*$ Mid & $\begin{array}{l}-0.053 \\
(0.511)\end{array}$ & $\begin{array}{l}-0.438 \\
(0.510)\end{array}$ & $\begin{array}{c}1.047 \\
(1.213)\end{array}$ & $\begin{array}{c}0.530 \\
(0.561)\end{array}$ & $\begin{array}{c}0.239 \\
(0.508)\end{array}$ \\
\hline alpha* $\operatorname{Mid} *[\sigma(\varepsilon) * 100]$ & & & $\begin{array}{l}-1.301 \\
(0.887)\end{array}$ & & \\
\hline alpha * High & $\begin{array}{c}2.343 * * * \\
(0.407)\end{array}$ & $\begin{array}{c}0.908 * * \\
(0.370)\end{array}$ & $\begin{array}{c}1.508 * * * \\
(0.443)\end{array}$ & $\begin{array}{c}2.056^{* * * *} \\
(0.443)\end{array}$ & $\begin{array}{c}0.590 \\
(0.484)\end{array}$ \\
\hline alpha * High * $\left[\sigma(\varepsilon)^{*} 100\right]$ & & & $\begin{array}{c}0.219 \\
(0.249)\end{array}$ & & \\
\hline adj. R-sq & $23.3 \%$ & $28.3 \%$ & $27.5 \%$ & $25.2 \%$ & $28.7 \%$ \\
\hline $\mathrm{N}$ & 20372 & 20372 & 19640 & 4766 & 4766 \\
\hline
\end{tabular}




\section{Table XII}

\section{Sensitivities of Management Fees to Different Proxies for Idiosyncratic Volatility}

In this table, we investigate the sensitivities of management fees to different proxies of idiosyncratic volatility and performance. We run a multivariate Fama-MacBeth (1973) regression in the period from January 1994 to December 2007. The dependent variable (expressed in percentage terms) is the fund management fees (operating expenses minus 12B-1 fees). The lagged control variables include: logarithm of TNA to proxy for the size of the fund; Fund Age, calculated as the logarithm of the number of months since fund inception; portfolio Turnover consisting of the aggregate sales or aggregate purchases of securities; Volatility of previous 12-month returns; N.Funds Family, computed as the number of funds in the family; Flows is the yearly percentage growth rate in fund net money flows. As proxies for fund idiosyncratic volatility we use the standard deviation of the residuals from different factor models: CAPM in column (i), Fama and French (1993) in column (ii), and Carhart (1997) from column (iii) to column (vii). As a robustness check, in columns (iii) to (vii) we estimate the sensitivities of fees to net raw returns in excess of the mean net returns of all funds with the same investment objective in that year. In the last four columns, we separate returns using the Sirri and Tufano (1998) piecewise performance rankings. In column (vi) we estimate the model in the subperiod from 1994 to 1999, while in column (vii) we re-estimate the model in the subperiod from 2000 to 2007 . We use the variable Small that equals 1 if the size of the fund is in the bottom 5\% in the fund size distribution in that year, and Star that equals 1 if the fund is part of a family comprising one or more funds which ranked in the top 5\% of the risk-adjusted performance distribution in that year. All regressions include untabulated dummies for share classes and investment objectives. Standard errors are in parentheses. One, two and three asterisks indicate statistical significance at the $10 \%, 5 \%$, and $1 \%$ level, respectively.

\begin{tabular}{|c|c|c|c|c|c|c|c|}
\hline & \multicolumn{7}{|c|}{ Yearly Management Fee (x 100) } \\
\hline & (i) & (ii) & (iii) & (iv) & (v) & (vi) & (vii) \\
\hline $\log$ TNA & $\begin{array}{c}-0.066^{* * *} \\
(0.007)\end{array}$ & $\begin{array}{c}-0.066^{* * *} \\
(0.007)\end{array}$ & $\begin{array}{c}-0.061^{* * *} \\
(0.008)\end{array}$ & $\begin{array}{c}-0.060 * * * \\
(0.008)\end{array}$ & $\begin{array}{c}-0.059^{* * * *} \\
(0.006)\end{array}$ & $\begin{array}{c}-0.073^{* * *} \\
(0.007)\end{array}$ & $\begin{array}{c}-0.048 * * * \\
(0.006)\end{array}$ \\
\hline Fund age & $\begin{array}{l}-0.001 \\
(0.005)\end{array}$ & $\begin{array}{l}-0.003 \\
(0.006)\end{array}$ & $\begin{array}{l}-0.001 \\
(0.008)\end{array}$ & $\begin{array}{c}0.009 \\
(0.009)\end{array}$ & $\begin{array}{c}0.009 \\
(0.006)\end{array}$ & $\begin{array}{c}0.000 \\
(0.009)\end{array}$ & $\begin{array}{c}0.015 \\
(0.008)\end{array}$ \\
\hline N.Funds Family & $\begin{array}{c}-0.002 * * * \\
(0.000)\end{array}$ & $\begin{array}{c}-0.002 * * * \\
(0.000)\end{array}$ & $\begin{array}{c}-0.002 * * * \\
(0.000)\end{array}$ & $\begin{array}{c}-0.003 * * * \\
(0.001)\end{array}$ & $\begin{array}{c}-0.002 * * * \\
(0.000)\end{array}$ & $\begin{array}{c}-0.004^{* * *} \\
(0.001)\end{array}$ & $\begin{array}{c}-0.001 * * * \\
(0.000)\end{array}$ \\
\hline Turnover & $\begin{array}{c}0.031 * * * \\
(0.006)\end{array}$ & $\begin{array}{c}0.024 * * * \\
(0.007)\end{array}$ & $\begin{array}{c}0.035 * * * \\
(0.005)\end{array}$ & $\begin{array}{c}0.051 * * * \\
(0.005)\end{array}$ & $\begin{array}{c}0.034 * * * \\
(0.005)\end{array}$ & $\begin{array}{c}0.041 * * * \\
(0.007)\end{array}$ & $\begin{array}{c}0.028 * * * \\
(0.007)\end{array}$ \\
\hline Flows & $\begin{array}{c}-0.027^{* *} \\
(0.010)\end{array}$ & $\begin{array}{c}-0.031 * * * \\
(0.010)\end{array}$ & $\begin{array}{c}-0.043^{* * *} \\
(0.007)\end{array}$ & $\begin{array}{c}-0.036^{* * *} \\
(0.009)\end{array}$ & $\begin{array}{c}-0.034^{* * * *} \\
(0.010)\end{array}$ & $\begin{array}{c}-0.033^{* * *} \\
(0.008)\end{array}$ & $\begin{array}{l}-0.036^{*} \\
(0.016)\end{array}$ \\
\hline Volatility & $\begin{array}{l}-2.125 \\
(1.256)\end{array}$ & $\begin{array}{l}-1.229 \\
(0.845)\end{array}$ & $\begin{array}{l}-0.922 \\
(0.598)\end{array}$ & $\begin{array}{c}3.101 * * * \\
(0.980)\end{array}$ & $\begin{array}{l}-1.052 \\
(0.866)\end{array}$ & $\begin{array}{l}-2.398 \\
(1.617)\end{array}$ & $\begin{array}{l}-0.043 \\
(0.834)\end{array}$ \\
\hline$\sigma(\varepsilon)$ & $\begin{array}{c}12.416^{* * * *} \\
(2.062)\end{array}$ & $\begin{array}{c}15.665^{* * * *} \\
(2.081)\end{array}$ & $\begin{array}{c}13.975^{* * *} \\
(2.396)\end{array}$ & & $\begin{array}{c}16.211 * * * \\
(2.462)\end{array}$ & $\begin{array}{c}11.018^{* * *} \\
(2.811)\end{array}$ & $\begin{array}{c}20.105 * * * \\
(3.227)\end{array}$ \\
\hline alpha (CAPM) & $\begin{array}{l}-0.232 \\
(0.161)\end{array}$ & & & & & & \\
\hline alpha (FamaFrench) & & $\begin{array}{l}-0.198 \\
(0.160)\end{array}$ & & & & & \\
\hline Raw Return & & & $\begin{array}{l}-0.259^{*} \\
(0.121)\end{array}$ & $\begin{array}{c}-0.405^{* *} \\
(0.153)\end{array}$ & $\begin{array}{l}-0.015 \\
(0.157)\end{array}$ & $\begin{array}{l}-0.381 \\
(0.224)\end{array}$ & $\begin{array}{c}0.261 \\
(0.166)\end{array}$ \\
\hline Mid Return & & & & $\begin{array}{l}-0.080^{*} \\
(0.038)\end{array}$ & $\begin{array}{c}-0.091 * * \\
(0.031)\end{array}$ & $\begin{array}{l}-0.122 * \\
(0.056)\end{array}$ & $\begin{array}{l}-0.069^{*} \\
(0.036)\end{array}$ \\
\hline High Return & & & & $\begin{array}{c}0.381 * * \\
(0.151)\end{array}$ & $\begin{array}{c}0.211 \\
(0.144)\end{array}$ & $\begin{array}{c}0.383 \\
(0.212)\end{array}$ & $\begin{array}{c}0.082 \\
(0.194)\end{array}$ \\
\hline D.Star & $\begin{array}{c}0.041 \\
(0.036)\end{array}$ & $\begin{array}{c}0.028 \\
(0.034)\end{array}$ & $\begin{array}{c}0.148 * * \\
(0.054)\end{array}$ & $\begin{array}{c}0.136^{* *} \\
(0.046)\end{array}$ & $\begin{array}{c}0.063 \\
(0.038)\end{array}$ & $\begin{array}{c}0.105 \\
(0.083)\end{array}$ & $\begin{array}{c}0.032 \\
(0.026)\end{array}$ \\
\hline D.Small & $\begin{array}{c}0.033 \\
(0.119)\end{array}$ & $\begin{array}{c}0.017 \\
(0.116)\end{array}$ & $\begin{array}{l}-0.051 \\
(0.058)\end{array}$ & $\begin{array}{c}-0.123 * * * \\
(0.030)\end{array}$ & $\begin{array}{c}-0.102 * * \\
(0.047)\end{array}$ & $\begin{array}{l}-0.061 \\
(0.109)\end{array}$ & $\begin{array}{c}-0.132 * * * \\
(0.018)\end{array}$ \\
\hline adj. R-sq & $28.2 \%$ & $25.8 \%$ & $24.3 \%$ & $20.0 \%$ & $23.9 \%$ & 0.295 & 0.229 \\
\hline $\mathrm{N}$ & 19640 & 19640 & 25378 & 28686 & 26082 & 7039 & 19043 \\
\hline
\end{tabular}


Figure 1

\section{Average Monthly Cross-sectional Fund Idiosyncratic Volatility}

This figure plots the average cross-sectional fund idiosyncratic volatilities calculated using low frequency monthly data for the sample period December 1992 to December 2007. We report the time series of the average idiosyncratic volatility computed as the standard deviation of the residuals from a Carhart (1997) four-factor model (dark-coloured line) and using the approach proposed by French, Schwert, and Stambaugh (1987) where we also adjust for the autocorrelation in monthly returns (light-coloured line). The correlation coefficient between these two measures is around 0.98 over the entire sample period.

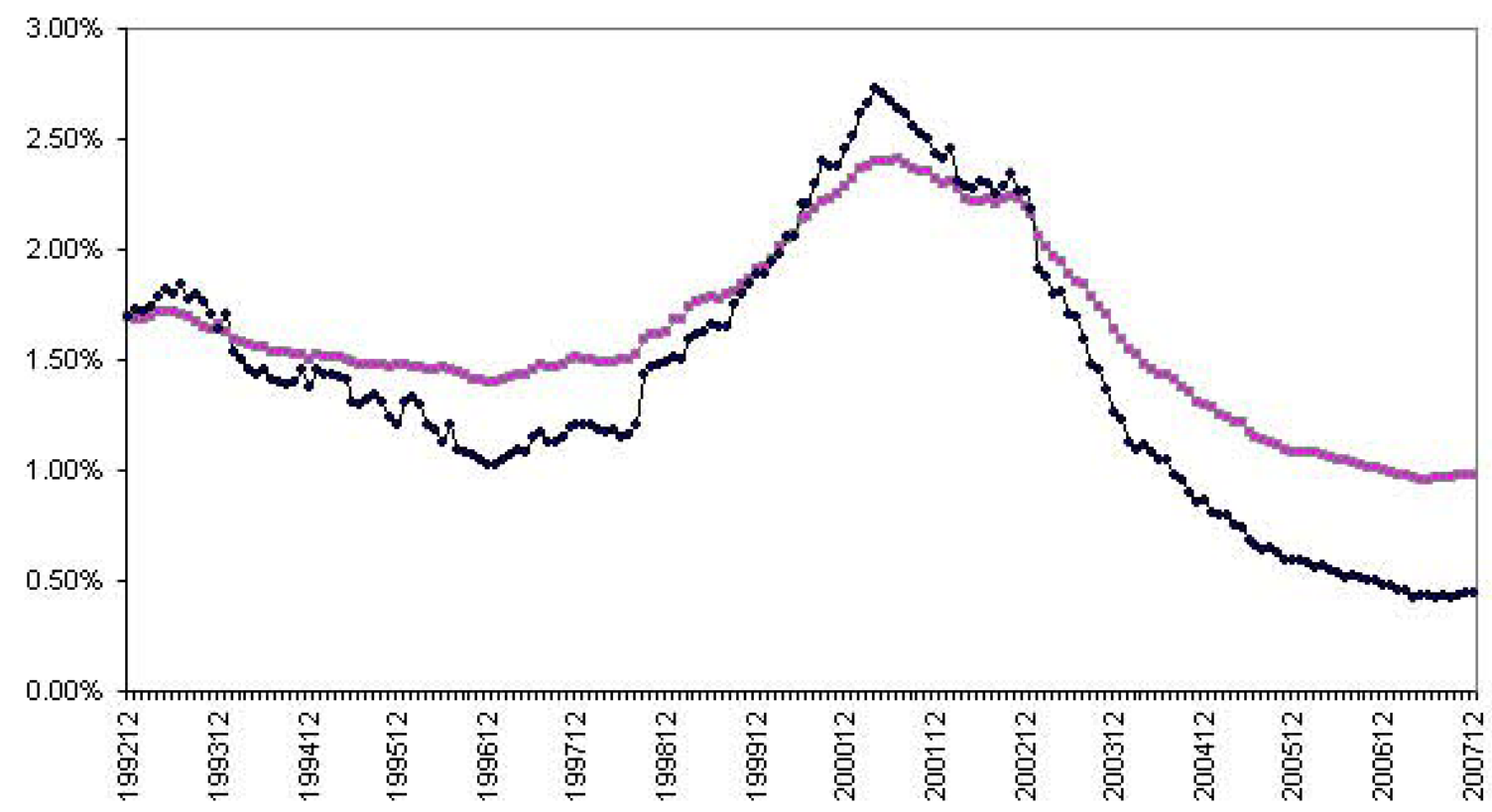

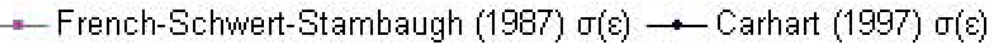




\section{Figure 2 \\ Probability Distribution Functions of Mutual Fund Returns by Portfolios of Idiosyncratic Volatility}

This figure plots the kernel densities of after-fee returns for our sample of diversified equity mutual funds over the period from 1994 to 2007. We first sort funds into deciles based on their estimated idiosyncratic volatility as in year $t-1$. For quintile 1, three, and five of idiosyncratic volatility, we then plot the (kernel) probability distributions of fund net returns of each quintile portfolio. In panel A, we report the density for the unconditional Carhart (1997) risk adjusted returns, while in panel $\mathrm{B}$ we repeat this exercise for fund realized raw returns.
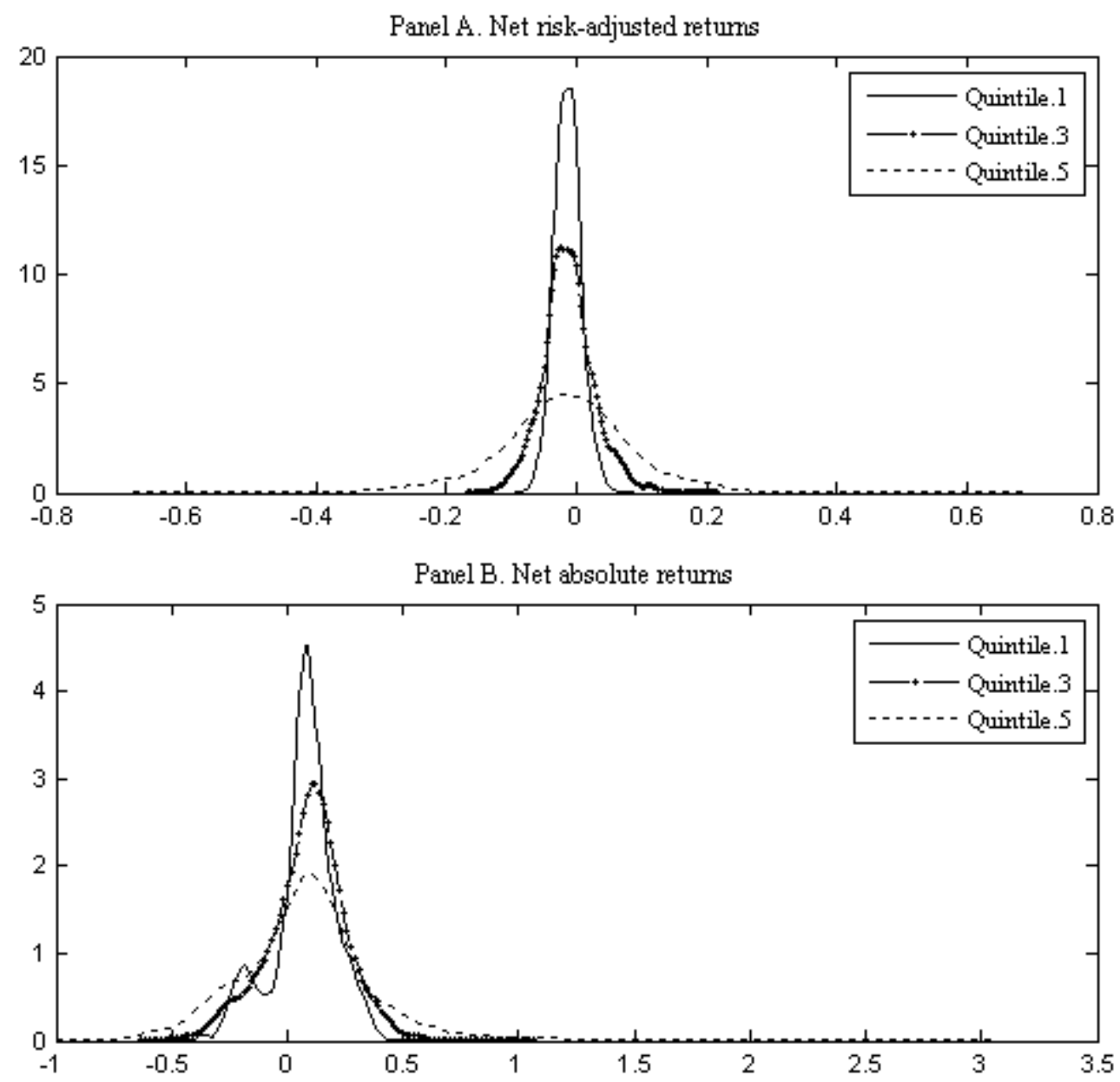


\section{Figure 3}

\section{Idiosyncratic Volatility, Fund Performance, and Management Fee}

In each of the 15 years over the entire period from 1994 to 2007 we sort after-fee returns in percentiles. We repeat this procedure to also build yearly percentiles of idiosyncratic volatility $(\sigma(\varepsilon))$. For each percentile of lagged idiosyncratic volatility, we compute the average values of the management fees (operating expenses minus 12B-1 fees) in the first subplot. In the second subplot, we document the average standard deviation of the residuals from the unconditional Carhart (1997) four-factor model estimated over the previous 36 months, across percentiles of fund performance. In the last subplot, instead, we calculate the average values of the management fees (operating expenses minus 12B-1 fees) across performance percentiles. We also graph the fifth degree polynomial interpolation (dotted line) as the best fit of each relationship.
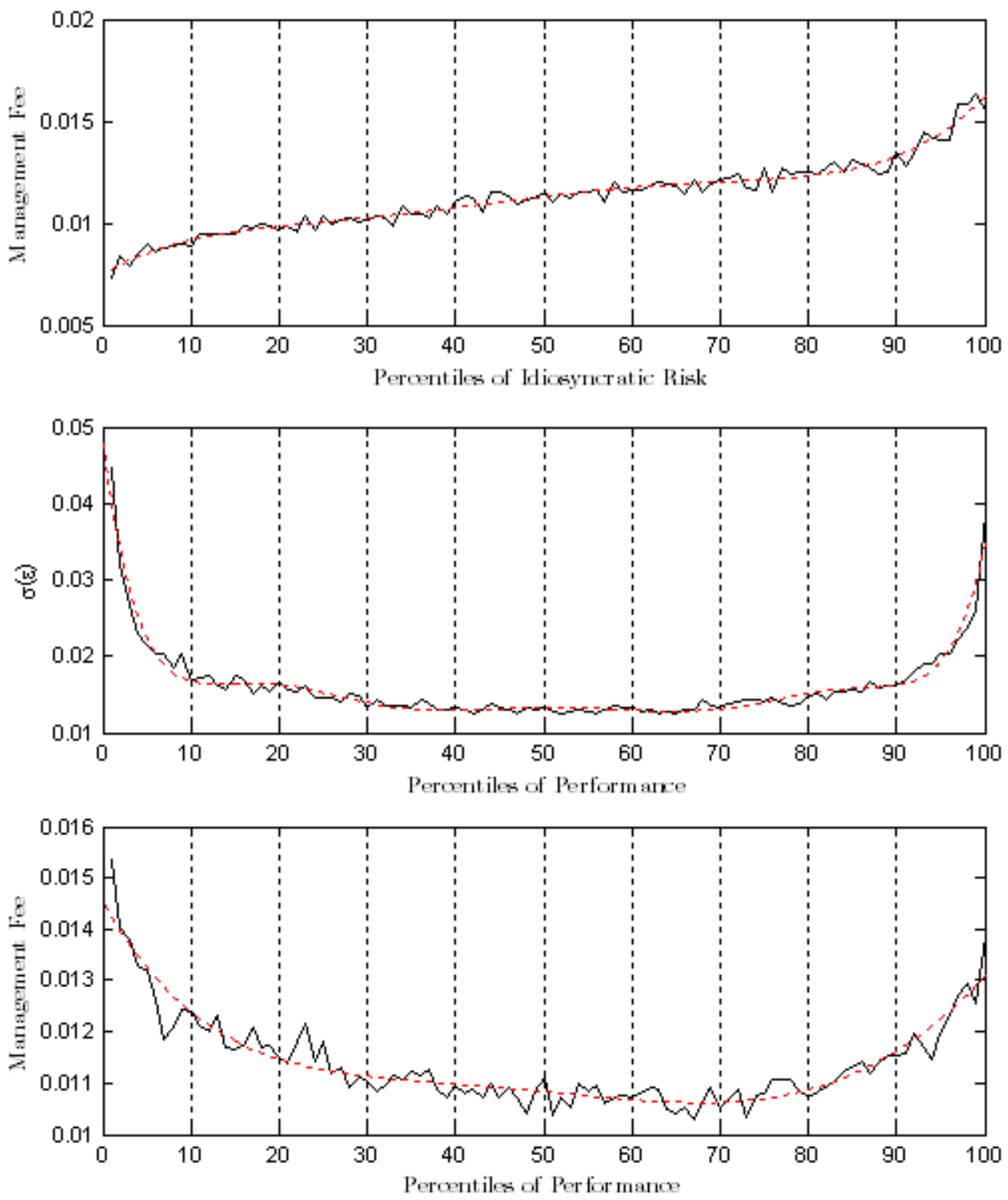
Figure 4

Simulated versus Actual Fee-Performance Relationship

In each of the 15 years over the entire sample period from 1994 to 2007 we sort lagged after-fee returns and lagged idiosyncratic risk $(\sigma(\varepsilon))$ in percentiles. For each of these percentiles, we then compute the average values of: (i) the standard deviation of the residuals from the Carhart (1997) model relative to ascending percentiles of performance, and (ii) the management fees (operating expenses minus 12B-1 fees) relative to ascending percentiles of idiosyncratic risk. In the second step, we search for the specific percentile of idiosyncratic volatility corresponding to the average idiosyncratic volatility resulting from each ascending percentile of performance. The fee corresponding to each of these identified percentiles of idiosyncratic volatility will constitute the simulated fee-performance relationship (solid line) as compared to the actual fee-performance relationship (dotted line).

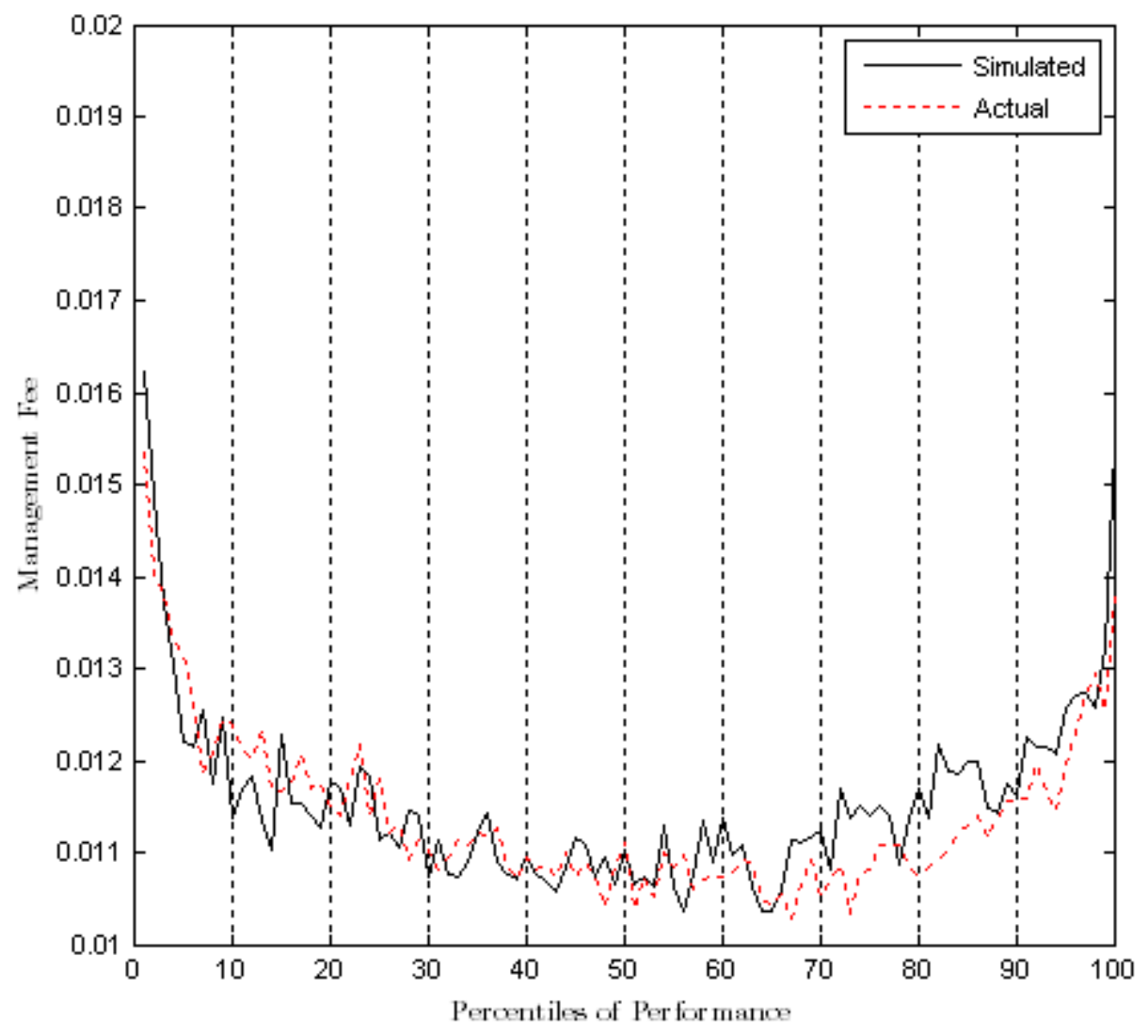

